\title{
PERFORMANCE OF DROUGHT INDICES FOR ECOLOGICAL, AGRICULTURAL AND HYDROLOGICAL APPLICATIONS
}

\author{
Sergio M. Vicente-Serrano ${ }^{1, *}$, Santiago Beguería ${ }^{2}$, Jorge Lorenzo-Lacruz ${ }^{1}$, Jesús Julio Camarero ${ }^{3}$, \\ Juan I. López-Moreno ${ }^{1}$, Cesar Azorin-Molina ${ }^{1}$, Jesús Revuelto ${ }^{1}$, Enrique Morán-Tejeda ${ }^{1}$ and Arturo \\ Sánchez-Lorenzo ${ }^{4}$ \\ ${ }^{1}$ Instituto Pirenaico de Ecología, Consejo Superior de Investigaciones Científicas (IPE-CSIC), Campus de \\ Aula Dei, P.O. Box 13034, E-50059, Zaragoza, Spain \\ ${ }^{2}$ Estación Experimental de Aula Dei, Consejo Superior de Investigaciones Científicas (EEAD-CSIC), \\ Zaragoza, Spain \\ ${ }^{3}$ ARAID-Instituto Pirenaico de Ecología, CSIC (Consejo Superior de Investigaciones Científicas), Campus \\ de Aula Dei, P.O. Box 13034, E-50059, Zaragoza, Spain \\ ${ }^{4}$ Institute for Atmospheric and Climate Science, ETH Zurich, Zurich, Switzerland \\ * Corresponding author: svicen@ipe.csic.es
}

\begin{abstract}
In this study we provide a global assessment of the performance of different drought indices for monitoring drought impacts on several hydrological, agricultural and ecological response variables. For this purpose, we compare the performance of several drought indices (the Standardized Precipitation Index, SPI; four versions of the Palmer Drought Severity Index, PDSI; and the Standardized Precipitation Evapotranspiration Index, SPEI) to predict changes in streamflow, soil moisture, forest growth and crop yield. We found a superior capability of the SPEI and the SPI drought indices, which are calculated on different time-scales, than the Palmer indices to capture the drought impacts on the aforementioned hydrological, agricultural and ecological variables. We detected small differences in the comparative performance of the SPI and the SPEI indices, but the SPEI was the drought index that best captured the responses of the assessed variables to drought in summer, the season in which more drought-related impacts are recorded and in which drought monitoring is critical. Hence, the SPEI index shows improved capability to identify drought impacts as compared with the SPI one. In conclusion, it seems reasonable to recommend the use of the SPEI if the responses of the variables of interest to drought are not known a priori.
\end{abstract}


Key-words: Drought index, drought vulnerability, agricultural droughts, dendrochronology, hydrological droughts, Standardized Precipitation Evapotranspiration Index (SPEI), Standardized Precipitation Index (SPI), Palmer Drought Severity Index (PDSI).

\section{Introduction}

Drought is among the most complex climatic phenomena affecting society and the environment (Wilhite, 1993). The root of this complexity is related to the difficulty of quantifying drought severity since we identify a drought by its effects or impacts on different types of systems (agriculture, water resources, ecology, forestry, economy, etc.), but there is not a physical variable we can measure to quantify droughts. Thus, droughts are difficult to pinpoint in time and space since it is very complex to identify the moment when a drought starts and ends, and also to quantify its duration, magnitude and spatial extent (Burton et al., 1978; Wilhite, 2000).

These characteristics explain the vast scientific effort devoted to develop tools providing an objective and quantitative evaluation of drought severity. The quantification of drought impacts is commonly done by using the so-called drought indices, which are proxies based on climatic information and assumed to adequately quantify the degree of drought hazard exerted on sensitive systems. Many studies have shown strong relationships between the temporal variability of different drought indices and response variables of natural systems such as tree growth (e.g., Orwig and Abrams, 1997; Copenheaver et al., 2011; Pasho et al., 2011), river discharge (e.g., Vicente-Serrano and López-Moreno, 2005; Hannaford et al., 2011), groundwater level (Khan et al., 2008; Fiorillo and Guadagno, 2010), crop yields (e.g., Vicente-Serrano et al., 2006; Vergni and Todisco, 2011), vegetation activity (e.g., Lotsch et al., 2003; McAuliffe and Hamerlynck, 2010; Vicente-Serrano, 2007), the frequency of forest fires (Littell et al., 2009; Drobyshev et al., 2012), etc. Drought indices are currently used to monitor drought conditions in real time manner that is easily understood by end users (Svoboda et al., 2002; Shukla et al., 2011). Indeed, drought monitoring has 
been recognized as crucial for the implementation of drought plans (Wilhite, 1996; Wilhite et al., 2007).

Recent works have reviewed the development of drought indices and compared their advantages and drawbacks (Heim, 2002; Keyantash and Dracup, 2002; Mishra and Singh, 2010; Sivakumar et al., 2010). However, very few studies have performed robust statistical assessments by comparing different drought indices which may allow recommending the preferential use of one of them based on objective criteria (Guttman, 1998; Keyantash and Dracup, 2002; Steinemann, 2003; Paulo and Pereira, 2006; Quiring, 2009; Vicente-Serrano et al., 2010; Barua et al., 2011; Anderson et al., 2011). In addition, few researchers have compared the relative performance of different drought indices to identify drought impacts on several systems. In the case of drought impacts on hydrological systems, Vasiliades et al., (2011) compared five drought indices in Greece. LorenzoLacruz et al. (2010) compared the performance of two drought indices to identify hydrological droughts in river discharges and reservoir storages in central Spain, and Zhai et al. (2010) compared the relationship between the Standardized Precipitation Index (SPI) and the Palmer Drought Severity Index (PDSI) and streamflow data in ten regions of China. Sims et al. (2002) compared the PDSI and the SPI to assess soil moisture variations in North Carolina, USA. In relation to vegetation activity and crop productivity, Potop (2011) compared different indices to assess drought impacts on corn yields in Moldava, and Mavromatis (2007) and Quiring and Papakryiakou (2003) followed a similar approach by quantifying wheat production in Greece and the Canadian prairies, respectively. Quiring and Ganesh (2010) compared drought indices to assess the responses of vegetation activity to drought severity in Texas (USA). Kempes et al. (2008) assessed tree-ring growth response to different drought indices in the southwestern USA. Recently, Drobyshev et al. (2012) analyzed the correlation between different drought indices and fire frequency in Sweden. The results of these studies are diverse, since the best drought index for detecting impacts changes as a function of the analyzed system and the performance of the drought indices varied spatially. As 
a result, at present there is high uncertainty among scientists, managers and end users of drought information when they aim to select one drought index for a specific purpose.

To the best of our knowledge, at present there is no global study analyzing and comparing to which degree the most widely used drought indices are able to identify drought impacts on vulnerable systems. This task is necessary in order to have solid and objective criteria for selecting a drought index to be used for specific tasks. In this study we provide the first global assessment of the performance of different drought indices for monitoring drought impacts on streamflows, soil moisture, forest growth and crop yields. For this purpose, we compare two of the most widely used drought indices, the Standardized Precipitation Index, SPI (McKee et al., 1993), and four versions of the Palmer Drought Severity Index, PDSI (Palmer, 1965). In addition, we also include in our comparison the recently developed Standardized Precipitation Evapotranspiration Index (SPEI), which has been claimed to outperform the two previous indices (Vicente-Serrano et al., 2010b).

\section{Datasets and methods}

\subsection{Drought indices}

\section{a) The Palmer Drought Indices}

The PDSI was a landmark in the development of drought indices. It enables measuring both wetness (positive value) and dryness (negative values), based on the supply and demand concepts of the water balance equation, and thus incorporates prior precipitation, moisture supply, runoff and evaporation demand at the surface level. Although the PDSI presents several deficiencies (Alley, 1984; Karl, 1986; Soulé, 1992; Akimremi et al., 1996; Weber and Nkemdirim, 1998; VicenteSerrano et al., 2011), currently it is still one of the most widely used drought indices. The PDSI is calculated based on precipitation and temperature data, as well as the water content of the soil. All the basic terms of the water balance equation can be determined from those inputs, including evapotranspiration, soil recharge, runoff, and moisture loss from the surface layer. The complete 
calculation procedure of the PDSI can be consulted in many publications (e.g., Karl, 1983 and 1986; Alley, 1984).

The modified Palmer Drought Severity Index (WPLM) was proposed by the National Weather Service Climate Analysis Center for operational meteorological purposes (Heddinghaus and Sabol 1991), modifying the original rules of accumulation during wet and dry spells.

The Palmer Hydrological Drought index (PHDI) was derived from the PDSI to quantify the longterm impact of drought on hydrological systems. Values of the PHDI tend to be negative for up to several months after PDSI have returned to normal levels, i.e. it usually returns to near-normal levels more gradually than the PDSI (Karl et al., 1987). Therefore, the PHDI is considered a measure of long-term hydrological drought since streamflows, reservoir storages and groundwater tend to stay below normal values for some time after a meteorological drought ends. Finally, the Palmer Z-Index is also derived from the Palmer model and it is much more responsive to short-term moisture deficiencies than the PDSI. The Palmer Z-Index shows how monthly moisture conditions depart from normal, and it is sensitive to unusual wet (and dry) months even in extended dry (or wet) spells. Therefore, the Palmer Z-index is usually used for the detection of short term droughts. One of the main problems of the Palmer indices is that the parameters necessary to calculate them were determined empirically and mainly tested in the USA, which restricts its use in other regions (see Akimremi et al., 1996) and limits the geographical comparisons based on the PDSI (Heim, 2002; Guttman et al., 1992). This problem was solved by developing of the self-calibrated Palmer indices (Wells et al., 2004), which are spatially comparable and report extreme wet and dry events at frequencies expected for rare conditions. Therefore, in this study we have used the self-calibrated versions of the four Palmer drought indices, which are more suitable for drought quantification and monitoring at a global scale than the corresponding Palmer indices.

\section{b) The Standardized Precipitation Index (SPI)}


The Standardized Precipitation Index (SPI) was proposed by McKee et al. (1993) and it has been increasingly used during the two last decades because of its solid theoretical development, robustness and versatility in drought analyses (Redmond, 2002). The SPI is based on the conversion of the precipitation data to probabilities based on long-term precipitation records computed on different time scales. Probabilities are transformed to standardized series with an average of 0 and a standard deviation of 1 . The main advantage of the SPI as compared with the Palmer indices is that the former allows analyzing drought impacts at different temporal scales while the latter does not (Edwards \& McKee, 1997). Further, the SPI is able to identify different drought types since particular systems and regions can respond to drought conditions at very different time scales. In the case of water resources, the advantages of the SPI have been illustrated in several studies (VicenteSerrano and López-Moreno, 2005; Szalai et al., 2000; Fiorillo and Guadagno, 2010; LorenzoLacruz et al., 2010; Khan et al., 2008; Vicente-Serrano et al., 2011). In addition, several studies have also demonstrated variation in the response of agricultural (Vicente-Serrano et al., 2006; Quiring and Ganesh, 2010) and ecological variables (Ji and Peters, 2003; Vicente-Serrano, 2007; Pasho et al., 2011) to different time scales of the SPI.

McKee et al. (1993) used the Gamma distribution to transform precipitation series to standardized units. Nevertheless, the frequency distributions of the precipitation series show significant changes that depended on the time scale (Vicente-Serrano, 2006). Among the different evaluated models, the Pearson III shows enhanced adaptability to precipitation series at different time scales (Guttman, 1999, Vicente-Serrano, 2006; Quiring, 2009). Therefore, here we use the algorithm described by Vicente-Serrano (2006) and López-Moreno and Vicente-Serrano (2008) to calculate 1- to 48-month SPI values based on the Pearson III distribution and the L-moments approach to obtain the distribution parameters.

c) The Standardized Precipitation Evapotranspiration Index (SPEI) 
The main criticism of the SPI is that its calculation is based only on precipitation data. The index does not consider other variables that can influence drought severity, since the SPI relies on two assumptions: i) the variability of precipitation is much higher than that of other variables, such as temperature and potential evapotranspiration (PET); and ii) the other variables are stationary (i.e. they have no temporal trend). The importance of variables other than precipitation is negligible in this framework, and droughts are assumed to be mainly controlled by the temporal variability of precipitation. Nevertheless, the role of warming-induced drought stress has been made evident in recent studies that analysed drought impacts on tree growth and mortality (e.g., Barber et al., 2000; Martínez-Villalta et al., 2008; Allen et al. 2010; Vicente-Serrano et al., 2010c; Carnicer et al., 2011; Camarero et al. 2011; Linares and Camarero, 2011) and on water resources (Cai and Cowan, 2008; Lespinas et al. 2010; Yulianti and Burn, 2006; Liang et al., 2010; Yang and Liu, 2011).

Therefore, the use of drought indices which include temperature data in their formulation, such as the PDSI, seems to be preferable than using indices without temperature information to identify warming-related drought impacts on different ecological, hydrological and agricultural systems. However, the PDSI lacks the multi-scalar character essential for assessing drought in relation to different hydrological systems, and also for differentiating among different drought types. The SPEI, based on precipitation and potential evapotranspiration, combines the sensitivity of PDSI to changes in evaporation demand, caused by temperature fluctuations and trends, with the simplicity of calculation and the multi-temporal nature of the SPI. The SPEI is based on a monthly climatic water balance (precipitation minus PET), which is adjusted using a 3-parameter log-logistic distribution. The values are accumulated at different time scales, following the same approach used in the SPI, and converted to standard deviations with respect to average values.

\subsection{Datasets}

The six drought indices here assessed (PDSI, PHDI, WPLM, Z-index, SPI and SPEI) were computed globally based on the CRU TS3.1 climate dataset (Mitchell and Jones, 2005; available 
online at http://badc.nerc.ac.uk/data/cru/), covering the period 1901-2009 at a spatial resolution of $0.5^{\circ}$. Given that the different hydrological, ecological and agricultural datasets used in this study contain temporal information available since 1948, and since the quality of the meteorological records in the CRU TS3.1 dataset is lower for the oldest records than for the most recent ones, we used only data for the period 1945-2009. Monthly precipitation and mean temperature were used to obtain the SPI and the SPEI at different time-scales. In addition, the different Palmer drought indices also required information on the water field capacity (Webb et al., 1993), which was obtained at a spatial resolution of $1^{\circ}$ from http://daac.ornl.gov/SOILS/guides/Webb.html.

To determine the performance of the different drought indices to quantify the impact on the analyzed systems we used global data of four different variables with hydrological, agricultural and ecological implications. On the one hand, we used monthly streamflow data, recorded from 1945 to 004, in 925 gauges at the mouth of hydrological basins across the world (Dai et al., 2009). From the original dataset we selected 151 gauges in which a maximum of the $15 \%$ of the data gaps were filled. The drainage basins of each gauge were determined based on the GTOPO30 Digital Elevation Model (Figure 1a). Monthly streamflow records were used to obtain a streamflow drought index, the Standardized Streamflow Index (SSI) (Vicente-Serrano et al., 2012), which allows performing spatial and temporal comparison between streamflow data independently of the river regimes and streamflow magnitudes. The gauging data correspond in some cases with managed river and in other cases with unmanaged ones. This difference is not a problem for the analyses, and it is even interesting to assess how drought indices may be used and adapted to determine hydrological droughts both in managed and unmanaged basins.

Global soil moisture data was acquired from the International Soil Moisture Network (Robock et al., 2000; available online at http://www.ipf.tuwien.ac.at/insitu/). Most of the series cover short periods or have data gaps, so we selected those series with a minimum of 10 years of data (Figure 1b). Some of the soil moisture stations provide daily or hourly data at different soil depths 
(commonly every $10 \mathrm{~cm}$ in depth from the top soil up to 1 or $1.5 \mathrm{~m}$ deep) whereas other stations provide monthly averages for the complete soil column from the top to $1 \mathrm{~m}$ deep. We homogenized all the existing information and converted the data to monthly averages of soil moisture for the soil column up to $1 \mathrm{~m}$ deep. Although the world soil moisture network uses different instruments and techniques (Dorigo et al., 2011) the measurements at the different sites are recorded in the same units (\% of the water field capacity) and given that each sample was compared independently with the different drought indices, the techniques of soil moisture measurements did not affect the analyses. Most of the soil moisture stations do not provide soil moisture data for winter months as a consequence of soil freezing or soil saturation during this season. For this reason the analyses focused on the period from April to October, when data were available for all the stations.

Concerning tree growth data, we compiled 1840 annual tree-ring width series or mean site chronologies encompassing the period 1945-2009 and archived by the National Climate Data Center (NCDC) in the International Tree-Ring Data Bank, ITRDB (Grissino-Mayer and Fritts, 1997; available online at: http://www.ncdc.noaa.gov/paleo/treering.html) (Figure 1c). Each chronology represents the average annual radial growth series of several trees (typically more than ten) of the same species growing in the same site. The wood samples are taken following standard dendrocrhonological protocols which include sampling at least ten trees within a stand, taking usually two radial cores per tree at 1.3 m (Fritts, 1976; Cook et al., 1990). The selected sites corresponded to those chronologies listed in the ITRDB with at least ten trees sampled after 1940, which we regarded as an acceptable criterion for robust replication within each site. Raw tree-ring widths are detrended and standardized to remove long term biological growth trends, associated with tree ageing and increasing trunk diameter, and most of the first-order temporal autocorrelation, although this transformation preserves the inter-annual and inter-decadal variability.

Crop yield data of wheat cultivations was obtained from the Food and Agricultural Organization (FAO; available online at http://faostat.fao.org) for the period 1960-2009. Wheat crops were 
selected because they have a widespread distribution across the world and because it is mostly a non-irrigated crop, and hence it presents a higher vulnerability to drought than other crops such as rice or corn. Time series of annual crop productions in 173 countries were selected considering only those time series with a minimum of 15 years of records. Since the wheat productions show a large linear trend that is attributable to technological advances in cropping systems, the series were detrended assuming a linear model for each country series following Lobell et al. (2011).

\subsection{Methods}

The different drought indices were calculated using the monthly precipitation and mean temperature of the CRU TS3.1 dataset. For the 151 basins we obtained the average precipitation and temperature for the entire basin from the same dataset. Therefore, we obtained one precipitation and one temperature series for each basin. In the case of the soil moisture and tree-ring width datasets we selected the $0.5^{\circ}$ precipitation and mean temperature series that corresponded to the location of the sample. In the case of the national wheat crop data we calculated a weighted average series of monthly precipitation and mean temperature over each country using the percent area covered by wheat crops in that country as a weighting factor. The percent surface covered by wheat crops in each pixel was obtained from the Harvest Choice web site (http://harvestchoice.org) at a spatial resolution of $0.5^{\circ}$ (see Figure $1 \mathrm{~d}$ ). The latitude necessary to obtain the SPEI and the Palmer indices, and the water field capacity used in the Palmer indices were also weighted for each country according to the percentage of surface cultivated by wheat.

Usually, the different hydrological, ecological and agricultural systems respond to different drought time scales due to the varied strategies of natural vegetation and crops to cope with water deficit (Chaves et al., 2003) or the different lithologic, land cover and/or water management regimes in the case of streamflow data (López-Moreno et al., 2012). Therefore, the SPI and the SPEI were calculated at different time scales from 1 up to 48 months. The multi-scalar character of these two 
drought indices is their major advantage as compared with other existing indices. Since the times of response to drought of the different systems is not known a priori, the Pearson correlation coefficients $(r)$ between the time series of these variables and the 1- to 48-month SPI and SPEI series were computed, and the time-scale at which the strongest correlation was found was kept for further analyses. The different Palmer indices were also correlated with the time-series of SSI, treering width, wheat yields and soil moisture. The monthly series of the different drought indices were detrended before calculating the Pearson coefficients between the drought indices and the annual tree-ring widths and wheat yields since the latter two series have been previously detrended to remove the respective effects of the tree ageing and technological advances on these variables.

\section{Results}

\subsection{Streamflow data}

Figure 2 shows a box plot illustrating the correlations obtained between the SSI series at 151 worldwide basins and the six assessed drought indices. Correlations were obtained for the continuous series between 1945 and 2004, independently of the month of the year, since the standardized character of the SSI allowed directly comparing with the drought indices at a monthly basis. In general, correlations tended to be higher for the SPI and the SPEI indices than for the Palmer ones (PDSI, PHDI, Z-index and WPLM). The median correlation coefficients for SPI and SPEI were 0.57 and 0.58 , respectively, whereas for the PDSI it was $0.45,0.39$ for the PHDI, 0.42 for the Z-index, and 0.46 for the WPLM. This shows that the SPI and SPEI tended to record better the occurrence of streamflow droughts than the Palmer indices. Figure 3 shows the same analyses at a monthly basis, since streamflow response to climatic droughts may be very different as a function of the river regimes. Higher correlations were found again for the SPI and SPEI than for other indices, irrespective of the month. It is interesting to note that differences in the magnitude of 
correlations between SPI and SPEI were minor for most of the analysed months, but for the boreal summer months the correlations tended to be marginally higher for the SPEI than for the SPI.

Figure 4 shows the spatial distribution of correlations between the SSI series and four of the most widely used drought indices (SPI, SPEI, PDSI, Z-index) either considering continuous series (Figure 4a) or separately for January (Figure 4b) and July (Figure 4c) monthly series. Large differences existed between basins. In general, and independently of the drought index used, the strongest correlations between SSI and drought severity were found for the Atlantic basins of North America, the basins of central Europe and some basins of South America and Africa. On the contrary, poor correlations were found in the Asian basins, mainly those that drain to the Arctic Ocean. Nevertheless, in the latter basins, when monthly correlations were analysed separately, noticeable seasonal impacts were observed since correlations were much higher in July (Figure 4c) than in January (Figure 4b). In addition, in these zones it is clearly observed that differences between the SPI and SPEI correlations were important during the summer months, with the SPEI showing higher correlations than the SPI. The PDSI had higher correlations in the northern north hemisphere latitudes during the summer months than the SPI, although it did not outperform the SPEI. Figure 4d shows the drought index with the highest SSI-drought correlation for the annual continuous series and for the January and July series. The Palmer indices did not provide the best results with respect to streamflow data with a few exceptions. For the continuous SSI data the best correlation was found using SPEI in $44.4 \%$ of the basins, the $38.4 \%$ with the SPI and the remaining 17.3\% with one of the four Palmer indices (Table 1). There were strong seasonal differences among areas since precipitation seems to be the main driver for the occurrence of streamflow droughts in the boreal winter when evapotranspiration rates are low, whereas in the boreal summer, when strong evapotranspiration rates are recorded in the Northern hemisphere, higher SSI-drought correlations were recorded when using the SPEI. 


\subsection{Soil moisture}

Figure 5 shows the box plots displaying the correlations between the different drought indices and the monthly soil moisture data obtained from April to October. Strong differences arise when comparing the SPI and the SPEI and the Palmer drought indices, with the first two indices outperforming the latter in all cases. It is interesting to note that correlations between soil moisture and drought indices were higher from July to October than for other months, being the former a period in which soils tend to be less saturated by water than in spring. The highest correlation between soil moisture and drought was found using the SPI or SPEI indices in a range of stations varying from $80 \%$ to $95 \%$ depending on the analyzed month, whereas in only 5 to $15 \%$ of the sites the highest correlation was found with the Palmer indices (Table 2). It was in the warmest months (July, August and September), in which evapotranspiration rates are the highest, when a much higher percentage of sites showed higher correlations with the SPEI than with the SPI. Figure 6 shows the spatial distribution of correlations between the July soil moisture and the July series of SPI, SPEI, PDSI and Z-Index for the sites available in North America and also the drought index at which the maximum correlation is found. Higher correlations are found again with the SPI and the SPEI. In addition, the SPEI shows the maximum correlation with soil moisture in most sites.

\subsection{Tree-ring width series}

Correlations between tree-ring width series and the drought indices are depicted in Figure 7. The median of the correlations oscillated between 0.44 for the SPI and 0.30 for the PHDI. The highest correlations were found during late spring and early summer, as it could be expected since most of the tree-ring series were located in the North hemisphere and most tree-ring growth occurs there during those seasons (Figure 8). There were very few differences in the magnitude of correlations between the SPI and the SPEI, but large differences were found between the Palmer drought indices. We show the spatial distribution of correlations for North America, in which the highest 
density of tree-ring width series was recorded. Figure 9a shows the maximum correlation found between the tree-ring width and several indices (SPI, SPEI, PDSI, Z-index). Higher growth-drought correlations were found in the central and southwestern areas of USA than elsewhere, being the former arid areas in which tree growth is highly driven by water availability. In humid sites of the East, North and North-West USA, where tree-ring growth is less constrained by drought, we obtain lower growth-drought correlations than elsewhere, independently of the selected drought index. Nevertheless, although the spatial pattern was quite similar considering the four drought indices, the magnitude of the correlations differed noticeably. In the areas with the highest growth-drought correlations of central and southwest USA, higher correlation values were found for the SPI and SPEI than for the Palmer drought indices. Figures 9b and 9c show correlations between annual tree growth and the series of the drought indices in January and July, respectively. Higher correlation coefficients were found in July than in January since higher growth activity is recorded in summer than in winter months. Again, higher growth-drought correlation values were also found for the SPI and the SPEI than for the PDSI and Z indices. With a few exceptions, the highest correlations in the different forests corresponded to the SPI or the SPEI (Figure 9d). The SPEI showed higher correlation values than the other drought indices in almost $50 \%$ of all analyzed sites (Table 3 ). The SPI showed the highest correlation in $37.9 \%$ of the forests. Only in the $13.7 \%$ of the forests the highest correlation corresponded to Palmer indices. Similar results were found at a monthly basis.

\subsection{Wheat crop yields}

A summary of the relationship between the global wheat yields and the six different drought indices is illustrated in the Figure 10, which records the maximum correlation between the annual wheat yields and the drought indices independently of the month of the year in which the highest correlation was found. This approach minimizes the impact of the different crop cycles and harvest dates in the different parts of the world. Stronger yield-drought correlations were obtained for the 
SPI and the SPEI than for the Palmer drought indices. However, important differences were found between the Palmer indices since the Z-index provided much better results than the other three indices. The median yield-drought correlation for the SPI was 0.33 , for the SPEI it was 0.37 and for the Z-index it was 0.29. Figure 11 shows the maximum correlation between the annual wheat yields and the evaluated drought indices. Large differences in the influence of drought conditions on wheat crop productions are evident across the world. Thus, the highest worldwide correlations were found in those countries in which the surface cultivated by wheat corresponds to semi-arid lands, which is the case of Russia, Kazakhstan, Australia, Morocco or Spain, among others (Figure 1d), in which correlations were higher than 0.5. In other regions of the world, the prevailing humid conditions or the irrigation may reduce the vulnerability of wheat crops to drought.

Nevertheless, independently of the existing spatial differences, we found that the yield-drought correlations tended to be higher for the SPI and the SPEI than for the PDSI and the Z-index with very few exceptions such as Australia, India or Angola. In any case, when the countries were classified according to the drought index showing the highest yield-drought correlation, we found that the wheat yields of most of the analyzed countries of the world were best correlated with the SPEI (49.5\%) or with the SPI (34.3\%). The percentage of countries in which the highest correlation was found with one of the different Palmer indices was quite low (2.9\% for the PDSI, 5.7\% for the PHDI, 2.9\% for the Z-index and 4.8\% for the WPLM). Excepting Australia and Ethiopia, which showed the highest yield-drought correlation when considering the WPLM index, the national wheat yields tended to be more closely correlated to the SPEI than to the other drought indices.

\section{Discussion and conclusions}

This study has provided the first global assessment of different indices to detect drought impacts on hydrological, ecological and agricultural systems. We must highlight the difficulty of developing this kind of studies based on empirical information given the existing methodological problems to 
quantify damages caused by water shortage on different systems that can be related to the severity of droughts. In addition, the global character of the study introduces other point of complexity given the varied sources of information and the need of an interdisciplinary approach.

We have used the two most widely drought indices worldwide. On the one hand, the Palmer drought indices that are currently implemented in drought monitoring systems, and the Standardized Precipitation Index (SPI), accepted by the World Meteorological Organization as the reference drought index for more effective drought monitoring and climate risk management (Hayes et al., 2011). In addition, we also included the Standardized Precipitation Evapotranspiration Index (SPEI), which is similar to the SPI but considers the influence of potential evapotranspiration on drought severity, in our analyses.

Independently of the hydrological, agricultural or ecological system analyzed we have found a higher capability of the drought indices that are calculated on different time scales, i.e. the SPEI and the SPI, to correlate with the temporal variability of the different variables. The Palmer indices, which lack the flexibility of reflecting the intrinsic multi-scalar nature of droughts, performed systematically worse than the SPI and SPEI.

The response of a specific system to drought can be very complex, and according to the analyzed system and its spatial location it may have large differences in the cumulative period of water deficit required causing negative impacts on the considered system (Vicente-Serrano et al., 2011). Different studies showed that particular systems and regions respond to drought conditions at different time scales, including hydrological (e.g., Szalai et al., 2000; Vicente-Serrano and LópezMoreno, 2005; Khan et al., 2008; Fiorillo and Guadagno, 2010; López-Moreno et al., 2012), agricultural (Quiring and Ganesh, 2010) and ecological variables (Ji and Peters, 2003; VicenteSerrano, 2007; Pasho et al., 2011). Thus, it is commonly accepted that dry conditions occur only during part of the hydrological cycle and so it is not usual to find simultaneous water deficits in soil moisture, streamflows, reservoir storages and groundwater. The problem is even more complex 
when diverse hydrological, agricultural, environmental and socioeconomic systems affected by droughts are considered, since the response times to water deficits and the resistance or resilience (ability to recover after the drought) of each system to drought can vary substantially. Therefore, although different Palmer indices representing various time scales of drought have been included in this analysis (Karl, 1986), they are not sufficiently flexible to quantify the strong variability in the response to droughts that can be found across a particular region. This is the rationale behind the results obtained in this article, which demonstrate that multi-scalar indices such as the SPI or the SPEI outperform other indices and allow adapting a wide range of drought vulnerabilities. The magnitudes of the correlations between various hydrological, agricultural and ecological variables and the compared drought indices clearly show that the SPI and the SPEI are more capable to monitor drought conditions in different systems. Thus, the highest correlation between the response variable and the drought index was found from $70 \%$ up to $95 \%$ of the cases for the SPI or the SPEI indices, depending of the variable and the season of the year, whereas the Palmer drought indices commonly represented less than the $15 \%$ of the highest correlations.

However, this finding does not mean that the Palmer indices are not useful for some purposes. For example, Dai et al. (2004) and Dai (2011) showed good correlations between the PDSI and annual streamflows and soil moisture worldwide. When monthly temporal scales are used,, the capability of the Palmer indices diminishes. Further, several studies have also found significant correlations of streamflow data (Alley, 1985; Smith and Richman, 1993; Tang and Piechota, 2009; Zhai et al., 2010), tree-ring width series (Meko et al., 1993; Orwing and Abrams, 1997; Piovesan et al., 2008) and crop yields (Akinremi et al., 1996; Quiring and Papakryiakou, 2003; Scian, 2004; Mavromatis, 2007) with monthly Palmer indices (commonly the PDSI). Probably, in all these systems stronger correlations would have been found considering different time scales of the SPI or the SPEI, but we must also note that globally, in some of the analyzed sites, the best response between the temporal variability of the different variables is found with one of the four Palmer drought indices. This 
highlights the necessity of testing and comparing the local performance of different drought indices to select the most appropriate one according to the variable of interest.

There are small differences in the performance of the SPI and the SPEI for capturing the variability of the studied systems since the magnitude of the correlations is similar between the two indices in many of the analyzed variables. This result could suggest the better use of the SPI regarding the SPEI since SPI has less data requirements. Nevertheless, some differences found between both indices must be emphasized, which suggests a better performance of the SPEI as compared with the SPI:

i) Independently of the variable of interest the SPEI renders higher correlations than the SPI. The SPEI recorded the highest percentage of cases showing the maximum variabledrought index correlations in all the analyzed variables. The difference in the percentage of maximum correlations between SPI and SPEI is about $10 \%$ higher for the SPEI than for the SPI in the different analyzed systems.

ii) The differences between the magnitude of correlations found for the SPI and the SPEI tend to be higher in the boreal summer, which represents the season in which soil moisture samples and forests are affected by drought stress in most of the analyzed sites, since most of them are located in the Northern hemisphere. Water demand by the atmosphere is higher in summer months than in other seasons due to higher incoming radiation and temperature. For this reason, in the season in which more drought-related impacts are recorded (water supply restrictions, decreased soil moisture, reduced tree growth, forest fires, etc.) and in which drought monitoring is more critical, the SPEI outperforms the SPI being the former index able to identify drought impacts better than the latter one.

These results clearly demonstrate that, although precipitation is the main driver of drought severity, the influence of the atmospheric evaporative demand cannot be neglected, mainly in the context of 
current global warming. Empirical studies have shown that temperature rise affects the severity of droughts. For example, Abramopoulos et al. (1988) used a general circulation model experiment to show that evaporation and transpiration can consume up to $80 \%$ of rainfall. The strong role of temperature as a major driver of drought severity was evident in the devastating 2003 central European heat wave, which drastically reduced tree growth and the Aboveground Net Primary Production (ANPP) across most of the continent (Ciais et al., 2005). Thus, observational and empirical studies have demonstrated that higher temperature increases drought stress and enhances forest mortality under water shortage (Adams et al., 2009; Allen et al. 2010). Warming processes are also involved in triggering the decline in world agricultural productions observed in the last years (Lobell et al., 2011). Zhao and Running (2010) have recently shown at a global scale that between 2000 and 2009 the annual ANPP decreased because of the combined effects of severe drought stress and high temperatures which induced high autotrophic respiration levels, indicating that ANPP decreases because of warming-associated drying trends.

Therefore, given the observed impacts of global warming processes on water availability and on related agricultural, ecological and hydrological systems, the expected future rise of temperatures (Solomon et al., 2007), and the results obtained in this study based on the objective comparison of different drought indices, it seems reasonable to recommend the use of the SPEI if a priori we do not know the possible response to drought of the variable of interest. Studies comparing the performance of several drought indices, like those evaluated here, would be preferable to determine the best drought index for identifying a certain drought type and its impacts on different systems. Nevertheless, this is sometimes expensive, time consuming and commonly there are not quantitative information and long time series of the variable of interest available to establish the comparisons. Therefore, the low data requirements of the SPEI, the facility and flexibility of its calculation, and the consideration of the two main elements that determine drought severity, namely precipitation and atmospheric evaporative demand, are solid reasons to recommend its use over other drought 
indices. In addition, we must also stress that the SPEI formulation used in this study was based on PET estimates obtained by means of the Thornthwaite equation, which only requires data of mean temperature and has some deficiencies to obtain reliable estimates of the variable (Donohue et al., 2010). Future improvements of the SPEI, including more reliable PET estimates based on the Hargreaves or Penman-Monteith equations, could reflect better the role played by PET on drought severity, and make the SPEI even more suitable to identify drought-related impacts across systems.

\section{Acknowledgements}

We would like to thank the Climate Research Unit of the University of East Anglia (UK) for providing the gridded precipitation and temperature data used in this study, Dr. Aiguo Dai of the National Center for Atmospheric Research (NCAR) for providing the global streamflow data, the International Soil Moisture Network for providing soil moisture dataset, Contributors of the International Tree-Ring Data Bank, IGBP PAGES/World Data Center for Paleoclimatology, NOAA/NCDC Paleoclimatology Program (Boulder, Colorado, USA) for providing the tree-ring data and the Food and Agricultural organization (FAO) for providing the wheat productions. This work has been supported by the research projects CGL2008-01189/BTE, CGL2011-27574-CO2-02, CGL2011-24185, CGL2011-26654 and CGL2011-27536 financed by the Spanish Commission of Science and Technology and FEDER, EUROGEOSS (FP7-ENV-2008-1-226487) and ACQWA (FP7-ENV-2007-1- 212250) financed by the VII Framework Programme of the European Commission, "Efecto de los escenarios de cambio climático sobre la hidrología superficial y la gestión de embalses del Pirineo Aragonés” financed by “Obra Social La Caixa” and the Aragón Government and "Influencia del cambio climático en el turismo de nieve” (CTTP01/10) financed by the Comisión de Trabajo de los Pirineos. JJC acknowledges the support of ARAID. 


\section{References}

Abramopoulos, F., C. Rosenzweig, and B. Choudhury, (1988): Improved ground hydrology calculations for global climate models (GCMs): Soil water movement and evapotranspiration. Journal of Climate, 1, 921-941.

Adams, H.D. et al., (2009): Temperature sensitivity of drought-induced tree mortality portends increased regional die-off under global-change-type drought. Proceedings of the National Academy of Sciences of the United States of America, 106: 7063-7066.

Allen, C.D., A.K. Macalady, H. Chenchouni, D. Bachelet, N. McDowell, M. Vennetier, T. Kizberger, A. Rigling, D.D. Breshears, E.H. Hogg, P. Gonzalez, R. Fensham, Z. Zhang, J. Castro, N. Demidova, J.H. Lim, G. Allard, S.W. Running, A. Semerci, and N. Cobb. (2010): A global overview of drought and heat-induced tree mortality reveals emerging climate change risks for forests. Forest Ecology and Management, 259, 660-684.

Alley, W.M., (1984): The Palmer drought severity index: limitations and applications. Journal of Applied Meteorology, 23, 1100-1109.

Alley, W.M., (1985): Palmer Drought Severity Index as a measure of hydrologica drought. Water Resources Bulletin, 21: 105-114

Anderson, M.C., Hain, C., Wardlow, B., Pimstein, A., Mecikalski, J.R., Kustas, W.P., (2011): Evaluation of drought indices based on Thermal remote sensing of evapotranspiration over the continental United States. Journal of Climate, 24: 2025-2044.

Akinremi, O.O., Mcginn, S.M., Barr, A.G., (1996): Evaluation of the Palmer Drought index on the Canadian prairies. Journal of Climate, 9: 897-905.

Barber, V.A., Juday, G.P., Finney, B.P., (2000): Reduced growth of Alaskan white spruce in the twentieth century from temperature-induced drought stress. Nature 405: 668-673.

Barua, S., Ng, A.W.M., Perera, B.J.C., (2011): Comparative Evaluation of Drought Indexes: Case Study on the Yarra River Catchment in Australia. Journal of Water Resources Planning and Management 137: 215-226.

Burton, I., R.W. Kates, and G.F. White, (1978): The environment as hazard. Oxford University Press. Nueva York, 240 pp.

Cai, W. and Cowan, T., (2008): Evidence of impacts from rising temperature on inflows to the Murray-Darling Basin. Geophysical Research Letters 35, art. no. L07701.

Camarero, J.J., Bigler, C., Linares, J.C. and Gil-Pelegrín, E. (2011): Synergistic effects of past historical logging and drought on the decline of Pyrenean silver fir forests. Forest Ecology and Management, 262, 759-769.

Carnicer, J., Coll, M., Ninyerola, M., Pons, X., Sánchez, G., Peñuelas, J., (2011): Widespread crown condition decline, food web disruption, and amplified tree mortality with increased climate change-type drought. Proceedings of the National Academy of Sciences of the United States of America, 108: 1474-1478.

Chaves, M.M., Maroco, J.P. and Pereira, J.S. (2003): Understanding plant responses to drought from genes to the whole plant. Functional Plant Biology 30, 239-264.

Ciais, Ph. et al. (2005). Europe-wide reduction in primary productivity caused by the heat and drought in 2003. Nature 437, 529-533.

Cook, E.R., and Kairiukstis, L.A. (1990): Methods of Dendrochronology. Kluwer Academic Publishers, Dordrecht, The Netherlands.

Copenheaver, C.A., Crawford, C.J. and Fearer, T.M., (2011): Age-specific responses to climate identified in the growth of Quercus alba. Trees - Structure and Function 25: 647-653.

Dai, A., Trenberth, K.E., Qian, T. (2004): A global dataset of Palmer Drought Severity Index for 1870-2002: Relationship with soil moisture and effects of surface warming. Journal of Hydrometeorology, 5: 1117-1130. 
Dai, A., T. Qian, K. E. Trenberth, and J. D Milliman, (2009): Changes in continental freshwater discharge from 1948-2004. J. Climate, 22: 2773-2791.

Dai, A. (2011), Characteristics and trends in various forms of the Palmer Drought Severity Index during 1900-2008, J. Geophys. Res., 116, D12115, doi:10.1029/2010JD015541.

Donohue, R.J., McVicar, T.R., Roderick, M.L., (2010): Assessing the ability of potential evaporation formulations to capture the dynamics in evaporative demand within a changing climate. Journal of Hydrology, 386: 186-197.

Dorigo, W. A., et al. (2011). The International Soil Moisture Network: a data hosting facility for global in situ soil moisture measurements, Hydrol. Earth Syst. Sci., 15: 1675-1698.

Drobyshev, I., Niklasson, M., Linderholm, H.W. (2012): Agricultural forest fire activity in Sweden: Climatic controls and geographical patterns in 20th century. Agricultural and Forest Meteorology, 154-155: 174-186

Edwards, D.C. and McKee, T.B., (1997): Characteristics of $20^{\text {th }}$ century drought in the United States at multiple time scales. Atmospheric Science Paper No. 634.

Fiorillo, F., Guadagno, F.M. (2010): Karst spring discharges analysis in relation to drought periods, using the SPI Water Resources Management, 24: 1867-1884.

Fritts, H.C. (1976): Tree Rings and Climate. Blackburn Press, Caldwell, New Jersey.

Grissino-Mayer H.D., Fritts, H.C., (1997): The International Tree-Ring Data Bank: an enhanced global database serving the global scientific community. The Holocene, 7: 235-238.

Guttman, N.B., Wallis, J.R. and Hosking, J.R.M., (1992): Spatial comparability of the Palmer Drought Severity Index. Water Resources Bulletin. 28: 1111-1119.

Guttman, N.B., (1998): Comparing the Palmer drought index and the Standardized Precipitation Index. Journal of the American Water Resources Association, 34, 113-121.

Guttman, N.B., (1999): Accepting the standardized precipitation index: a calculation algorithm. Journal of the American Water Resources Association. 35: 311-322.

Hannaford, J., Lloyd-Hughes, B., Keef, C., Parry, S., Prudhomme, C. (2011): Examining the largescale spatial coherence of European drought using regional indicators of precipitation and streamflow deficit Hydrological Processes 25: 1146-1162.

Hayes, M., M. Svoboda, N. Wall, and M. Widhalm (2011), The Lincoln Declaration on Drought Indices: Universal Meteorological Drought Index recommended, Bull. Am. Meteorol. Soc., 92, 485-488.

Heddinghaus, T. R. and P. Sabol, (1991). A review of the Palmer Drought Severity Index and where do we go from here? In: Proc. 7th Conf. on Applied Climatology, September 10-13,1991. American Meteorological Society, Boston, pp. 242-246.

Heim, R.R., (2002): A review of twentieth-century drought indices used in the United States. Bulletin of the American Meteorological Society, 83, 1149-1165.

Ji, L. and A.J. Peters, (2003): Assessing vegetation response to drought in the northern Great Plains using vegetation and drought indices. Remote Sensing of Environment, 87, 85-98.

Karl, T.R., (1986): The sensitivity of the Palmer Drought Severity Index and the Palmer z-Index to their calibration coefficients including potential evapotranspiration. Journal of Climate and Applied Meteorology, 25, 77-86.

Karl, T.R., (1986): The sensitivity of the Palmer Drought Severity Index and the Palmer z-Index to their calibration coefficients including potential evapotranspiration. Journal of Climate and Applied Meteorology, 25: 77-86.

Karl. T.R., Quinlan, F. and Ezell, D.D., (1987): Drought termination and amelioriation: its climatological probability. Journal of Climate and Applied Meteorology. 26: 1198-1209.

Kempes, C.P., O.B. Myers, D.D. Breshears, and J.J. Ebersole, (2008): Comparing response of Pinus edulis tree-ring growth to five alternate moisture indices using historic meteorological data. Journal of Arid Environments, 72, 350-357. 
Keyantash, J. and J. Dracup., (2002): The quantification of drought: an evaluation of drought indices. Bulletin of the American Meteorological Society, 83, 1167-1180.

Khan, S., H.F. Gabriel, and T. Rana, (2008): Standard precipitation index to track drought and assess impact of rainfall on watertables in irrigation areas. Irrigation and Drainage Systems, 22, 159-177.

Lespinas, F., Ludwig, W. and Heussner, S., (2010): Impact of recent climate change on the hydrology of coastal mediterranean rivers in Southern France. Climatic Change, 99: 425456.

Liang, S., Ge, S., Wan, L. and Zhang, J., (2010): Can climate change cause the Yellow River to dry up?. Water Resources Research, 46, W02505, doi:10.1029/2009WR007971.

Linares, J. C. and Camarero, J. J. (2011). From pattern to process: linking intrinsic water-use efficiency to drought-induced forest decline. Global Change Biology. doi: 10.1111/j.13652486.2011.02566.x

Littell, J.S., Mckenzie, D., Peterson, D.L., Westerling, A.L. (2009): Climate and wildfire area burned in western U.S. ecoprovinces, 1916-2003 Ecological Applications 19: 1003-1021

Lobell, D. A., Schlenker, W., Costa-Roberts. (2011): Trends and global crop production since 1980. Science, DOI:10.1126/science.1204531

López-Moreno, J.I. and Vicente-Serrano, S.M., (2008) Extreme phases of the wintertime North Atlantic Oscillation and drought occurrence over Europe: a multi-temporal-scale approach. Journal of Climate 21, 1220-1243.

López-Moreno, J.I., S.M., Vicente-Serrano, J. Zabalza, S. Beguería, J. Lorenzo-Lacruz, C. AzorinMolina, E. Morán-Tejeda. (2012) Hydrological response to climate variability at different time scales: a study in the Ebro basin. Journal of Hydrology. Under review.

Lorenzo-Lacruz, J., Vicente-Serrano, S.M., López-Moreno, J.I., Beguería, S., García-Ruiz, J.M., Cuadrat, J.M. (2010) The impact of droughts and water management on various hydrological systems in the headwaters of the Tagus River (central Spain). Journal of Hydrology, 386: 13-26.

Lotsch, A., Friedl, M.A., Anderson, B.T., Tucker, C.J. (2003): Coupled vegetation-precipitation variability observed from satellite and climate records. Geophysical Research Letters 30: CLM 8-1 - 8-4

Martínez-Villalta, J., López, B.C., Adell, N., Badiella, L., Ninyerola, M., (2008): Twentieth century increase of Scots pine radial growth in NE Spain shows strong climate interactions. Global Change Biology 14, 2868-2881.

Mavromatis, T., (2007): Drought index evaluation for assessing future wheat production in Greece. International Journal of Climatology, 27, 911-924.

Meko, D., Cook, E.R., Stahle, D.W., Stockton, C.W., Hughes, M.K. (1993): Spatial patterns of treegrowth anomalies in the United States and southeastern Canada. Journal of Climate 6: 17731786

McAuliffe, J.R., Hamerlynck, E.P. (2010): Perennial plant mortality in the Sonoran and Mojave deserts in response to severe, multi-year drought Journal of Arid Environments 74: 885-896

McKee, T.B.N., J. Doesken, and J. Kleist, (1993): The relationship of drought frecuency and duration to time scales. Eight Conf. On Applied Climatology. Anaheim, CA, Amer. Meteor. Soc. 179-184.

Mishra, A. K., and V. P. Singh (2010), A review of drought concepts, J. Hydrol., 391, 202-216.

Mitchell, T. D., and P. D. Jones (2005), An improved method of constructing a database of monthly climate observations and associated high resolution grids, Int. J. Climatol., 25, 693-712.

Orwig, D.A., Abrams, M.D. (1997): Variation in radial growth responses to drought among species, site, and canopy strata Trees - Structure and Function 11: 474-484

Palmer, W.C., (1965): Meteorological droughts. U.S. Department of Commerce Weather Bureau Research Paper 45, 58 pp. 
Pasho, E., J. Julio Camarero, Martín de Luis and Vicente-Serrano, S.M. (2011) Impacts of drought at different time scales on forest growth across a wide climatic gradient in north-eastern Spain. Agricultural and Forest Meteorology. 151: 1800-1811.

Paulo, A.A., Pereira, L.S. (2006): Drought concepts and characterization: Comparing drought indices applied at local and regional scales Water International 31: 37-49

Piovesan, G., Biondi, F., Di Filippo, A., Alessandrini, A., Maugeri, M. (2008): Drought-driven growth reduction in old beech (Fagus sylvatica L.) forests of the central Apennines, Italy Global Change Biology 14: 1265-1281

Potop, V. (2011): Evolution of drought severity and its impact on corn in the Republic of Moldova Theoretical and Applied Climatology 105: 469-483.

Quiring, S.M., Papakryiakou, T.N. (2003): An evaluation of agricultural drought indices for the Canadian prairies Agricultural and Forest Meteorology 118: 49-62

Quiring, S.M. (2009): Developing objective operational definitions for monitoring drought. Journal of Applied Meteorology and Climatology 48: 1217-1229

Quiring, S.M., Ganesh, S. (2010): Evaluating the utility of the Vegetation Condition Index (VCI) for monitoring meteorological drought in Texas Agricultural and Forest Meteorology 150: 330-339

Redmond, K.T., (2002): The depiction of drought. Bulletin of the American Meteorological Society, 83, 1143-1147.

Robock, A., Vinnikov, K.Y., Srinivasan, G., Entin, J.K., Hollinger, S.E., Speranskaya, N.A., Liu, S., Namkhai, A. (2000): The Global Soil Moisture Data Bank Bulletin of the American Meteorological Society 81: 1281-1299

Scian, B., Don, M. (1997): Retrospective analysis of the palmer drought severrity index in the semiarid Pampas Region, Argentina International Journal of Climatology 17:. 313-322

Shukla, S., Steinemann, A.C., Lettenmaier, D.P. (2011): Drought monitoring for Washington State: Indicators and applications Journal of Hydrometeorology 12: 66-83

Sims, A.P., D.S. Nigoyi, and S. Raman, (2002): Adopting indices for estimating soil moisture: A North Carolina case study. Geophysical Research Letters, 29, 1183, doi:10.1029/2001GL013343.

Sivakumar, M. V. K., R. P. Motha, D. A. Wilhite, and D. A. Wood (Eds.) (2010): Agricultural Drought Indices: Proceedings of an Expert Meeting, 2-4 June 2010, Murcia, Spain, 219 pp., World Meteorol. Org., Geneva, Switzerland.

Smith, K., Richman, M.B. (1993): Recent hydroclimatic fluctuations and their effects on water resources in Illinois Climatic Change 24: 249-269

Solomon, S. et al. (2007) Climate Change 2007: The Physical Science Basis. Cambridge University Press, Cambridge, United Kingdom and New York, NY, USA.

Soulé, P.T., (1992): Spatial patterns of drought frecuency and duration in the contiguous USA based on multiple drought event definitions. International Journal of Climatology, 12, 1124.

Svoboda, M., LeCompte, D., Hayes, M., Heim, R., Gleason, K., Angel, J., Rippey, B., Tinker, R., Palecki, M., Stooksbury, D., Miskus, D. and Stephens, S., (2002): The drought monitor. Bulletin of the American Meteorological Society. 83: 1181-1190.

Steinemann, A. (2003): Drought indicators and triggers: A stochastic approach to evaluation Journal of the American Water Resources Association 39: 1217-1233

Szalai, S., C.S. Szinell, and J. Zoboki, (2000): Drought monitoring in Hungary. In Early warning systems for drought preparedness and drought management. World Meteorological Organization. Lisboa: 182-199.

Tang, C., Piechota, T.C. (2009): Spatial and temporal soil moisture and drought variability in the Upper Colorado River Basin Journal of Hydrology 379: 122-135 
Vasiliades, L., Loukas, A., Liberis, N. (2011): A Water Balance Derived Drought Index for Pinios River Basin, Greece Water Resources Management 25: 1087-1101

Vergni, L., Todisco, F. (2011): Spatio-temporal variability of precipitation, temperature and agricultural drought indices in Central Italy. Agricultural and Forest Meteorology 151: 301313

Vicente-Serrano, S.M. and López-Moreno, J.I., (2005), Hydrological response to different time scales of climatological drought: an evaluation of the standardized precipitation index in a mountainous Mediterranean basin. Hydrology and Earth System Sciences 9: 523-533.

Vicente-Serrano, S.M., (2006), Differences in spatial patterns of drought on different time scales: an analysis of the Iberian Peninsula. Water Resources Management 20: 37-60.

Vicente-Serrano, S.M., Cuadrat, J.M. and Romo, A., (2006), Early prediction of crop productions using drought indices at different time scales and remote sensing data: application in the Ebro valley (North-east Spain). International Journal of Remote Sensing 27: 511-518.

Vicente-Serrano, S.M. (2007), Evaluating The Impact Of Drought Using Remote Sensing In A Mediterranean, Semi-Arid Region, Natural Hazards, 40: 173-208.

Vicente-Serrano, S.M., Beguería, S., López-Moreno, J.I., Angulo, M., El Kenawy, A. (2010a): A new global $0.5^{\circ}$ gridded dataset (1901-2006) of a multiscalar drought index: comparison with current drought index datasets based on the Palmer Drought Severity Index. Journal of Hydrometeorology. 11: 1033-1043

Vicente-Serrano S.M., Santiago Beguería, Juan I. López-Moreno, (2010b) A Multi-scalar drought index sensitive to global warming: The Standardized Precipitation Evapotranspiration Index - SPEI. Journal of Climate 23: 1696-1718.

Vicente-Serrano, S.M., Lasanta, T., Gracia, C., (2010c): Aridification determines changes in leaf activity in Pinus halepensis forests under semiarid Mediterranean climate conditions. Agricultural and Forest Meteorology 150, 614-628.

Vicente-Serrano, S.M., Beguería, S. and Juan I. López-Moreno (2011). Comment on "Characteristics and trends in various forms of the Palmer Drought Severity Index (PDSI) during 1900-2008” by A. Dai. Journal of Geophysical Research-Atmosphere. 116, D19112, doi:10.1029/2011JD016410

Vicente-Serrano, S.M., Juan I. López-Moreno, Santiago Beguería, Jorge Lorenzo-Lacruz, Cesar Azorin-Molina and Enrique Morán-Tejeda, (2012): Accurate computation of a streamflow drought index. Journal of Hydrologic Engineering doi:10.1061/(ASCE)HE.19435584.0000433

Webb, R.S., C.E. Rosenzweig, and E.R. Levine, (1993): Specifying land surface characteristics in general circulation models: soil profile data set and derived water-holding capacities. Global Biogeochemical Cycles, 7, 97-108.

Weber, L., and L.C. Nkemdirim, (1998): The Palmer drought severity index revisited. Geografiska Annaler, 80A, 153-172.

Wells, N., S. Goddard, and M.J. Hayes, (2004): A self-calibrating Palmer Drought Severity Index. Journal of Climate, 17, 2335-2351.

Wilhite, D.A., (1993): Drought assessment, management and planning: Theory and case studies. Kluwer. Boston.

Wilhite, D.A., (1996): A methodology for drought preparedness. Natural Hazards. 13: 229-252.

Wilhite, D.A., (2000): Drought as a natural hazard: concepts and definitions. In Drought: a global assessment. (D. Wilhite ed.). Vol 1: 3-18.

Wilhite, D. A., M. D. Svoboda, and M. J. Hayes (2007): Understanding the complex impacts of drought: A key to enhancing drought mitigation and preparedness, Water Resour. Manage., 21, 763-774, doi:10.1007/ s11269-006-9076-5.

Yang, Z and Liu, Q., (2011): Response of streamflow to climate changes in the yellow river basin, China. Journal of Climate, 12: 1113-1126. 
Yulianti, J.S. y Burn, D.H., (2006): Investigating links between climatic warming and low streamflow in the Prairies region of Canada. Geophysical Research Letters, 33: L20403.

Zhai, J., Su, B., Krysanova, V., Vetter, T., Gao, C., Jiang, T. (2010): Spatial variation and trends in PDSI and SPI indices and their relation to streamflow in 10 large regions of china Journal of Climate 23: 649-663.

Zhao, M. and Running, S.W. (2009): Drought-induced reduction in global terrestrial net primary production from 2000 through 2009. Science 329, 940-943. 
A)

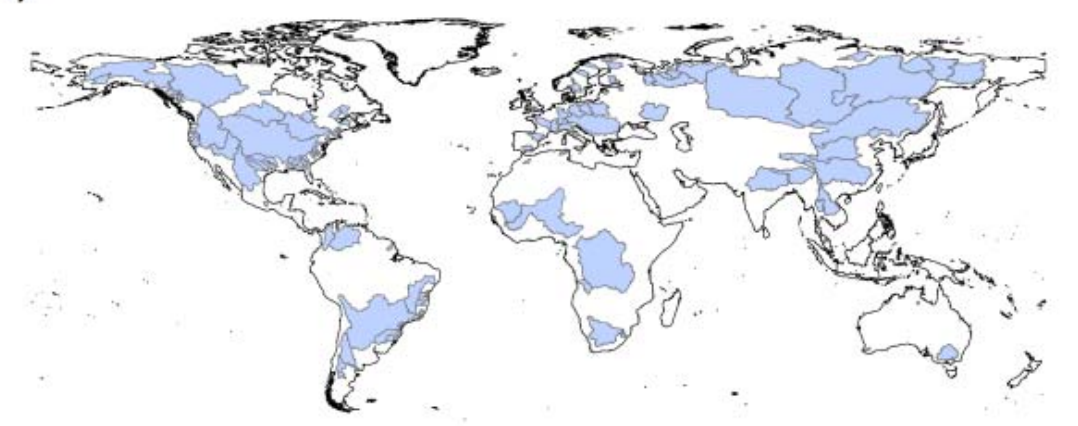

C)

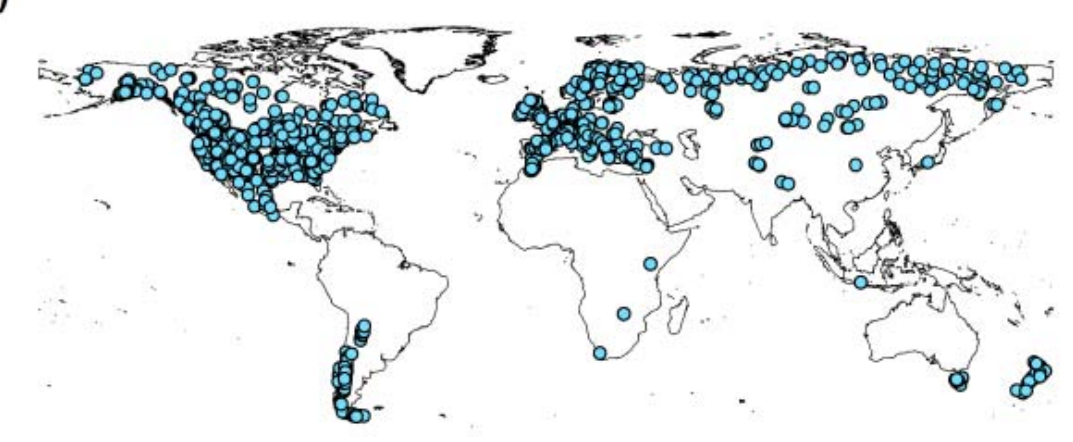

B)

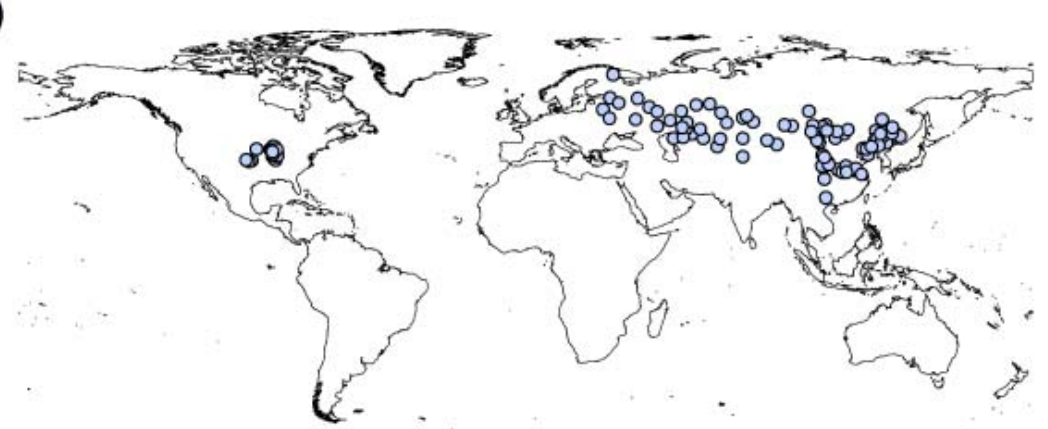

D)

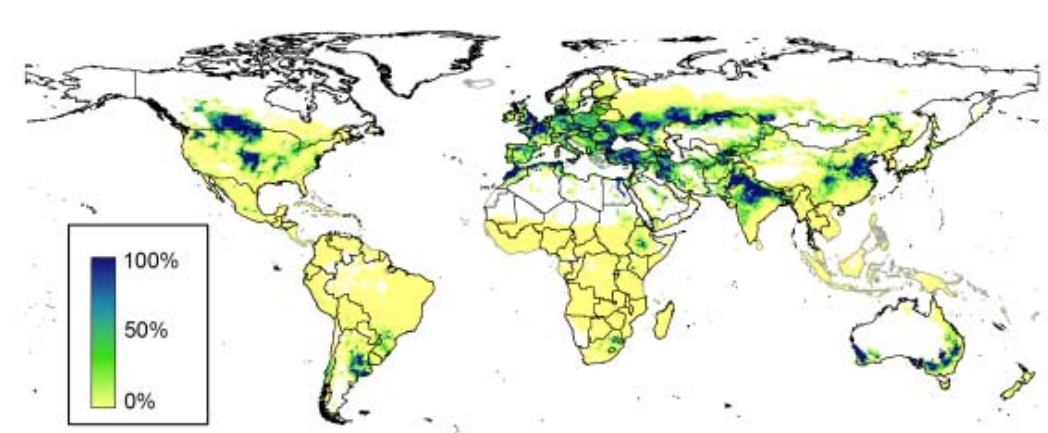

Figure 1. Response variables used in this study: A) Basins with monthly streamflow data for the period 1945-2004, B) soil moisture sample series with at least 10 years with data for the period 1950-2009, C) tree-ring width series with at least 25 years of data for the period 1945-2009,

D) countries with series of wheat productions with at least 10 years of data for the period 1960-2009 (black outline). In D) the colors represent the percentage of lands cultivated by wheat, which was used as a weight to obtain the precipitation and temperature series, the water field capacity and the latitude used to obtain the time series of drought indices for each country. 


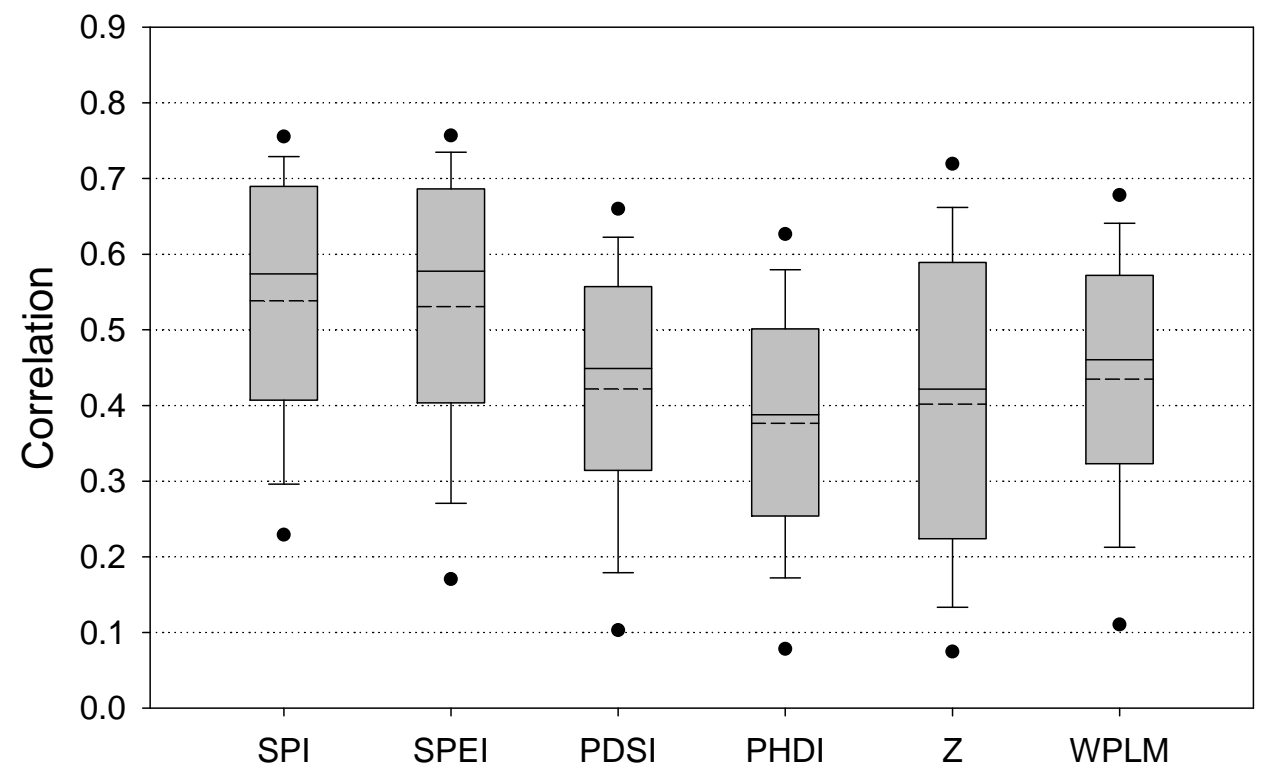

Figure 2. Box plots (the solid and dashed lines within the boxes correspond to the median and mean values, respectively) showing the correlations (Pearson coefficient) between the continuous series of the Standardized Streamflow Index (SSI) in 151 basins across the world and the six drought indices compared in this study. 

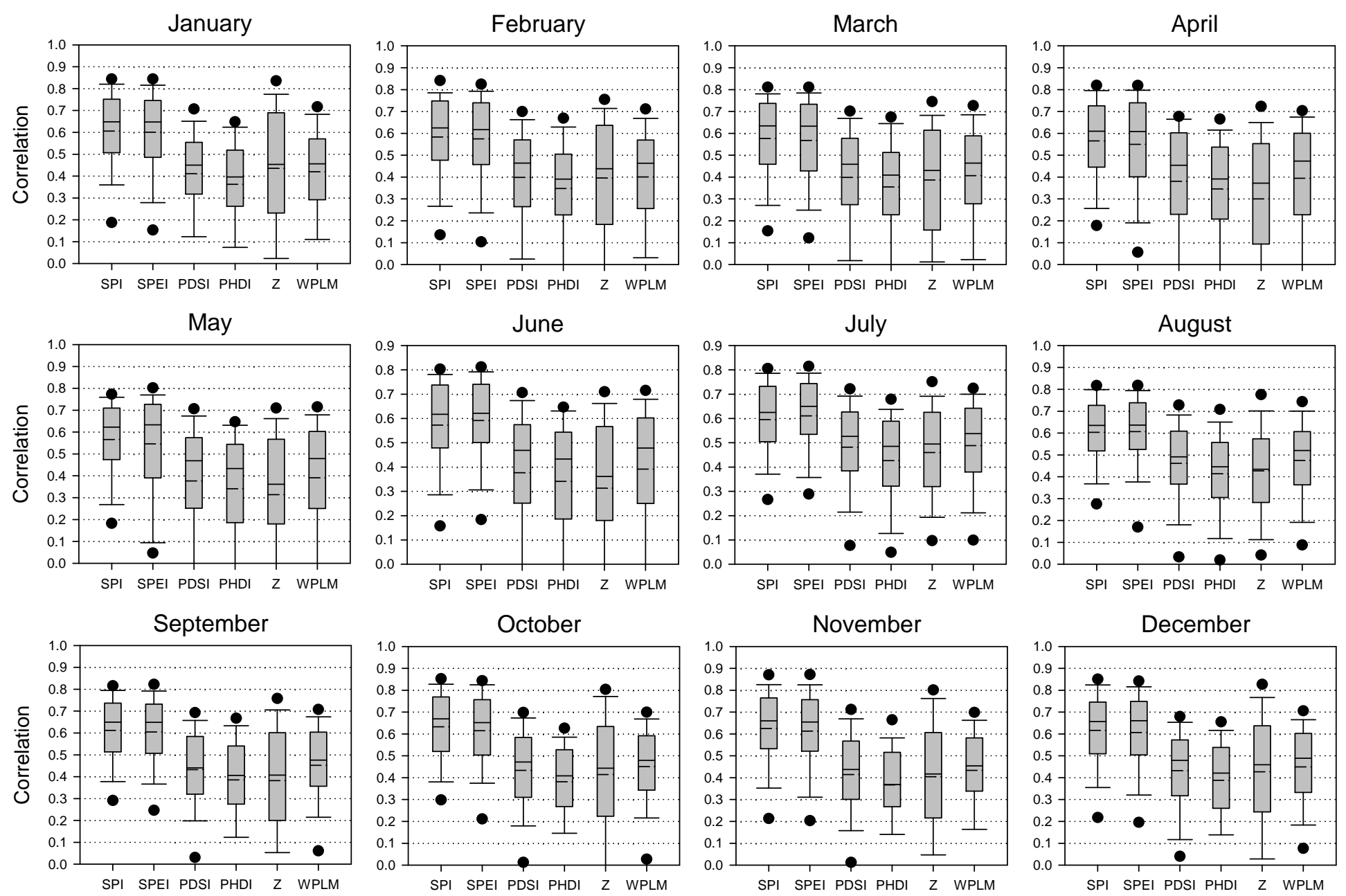

Figure 3. Box plots showing the correlations between the monthly series of the Standardized Streamflow Index (SSI) in 151 basins across the world and the six drought indices compared in this study. 


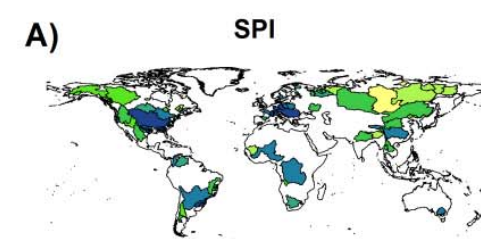

SPI

B)

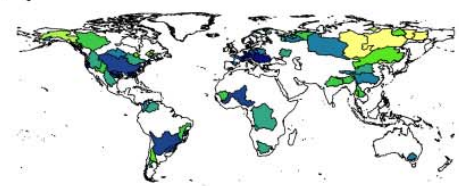

SPI
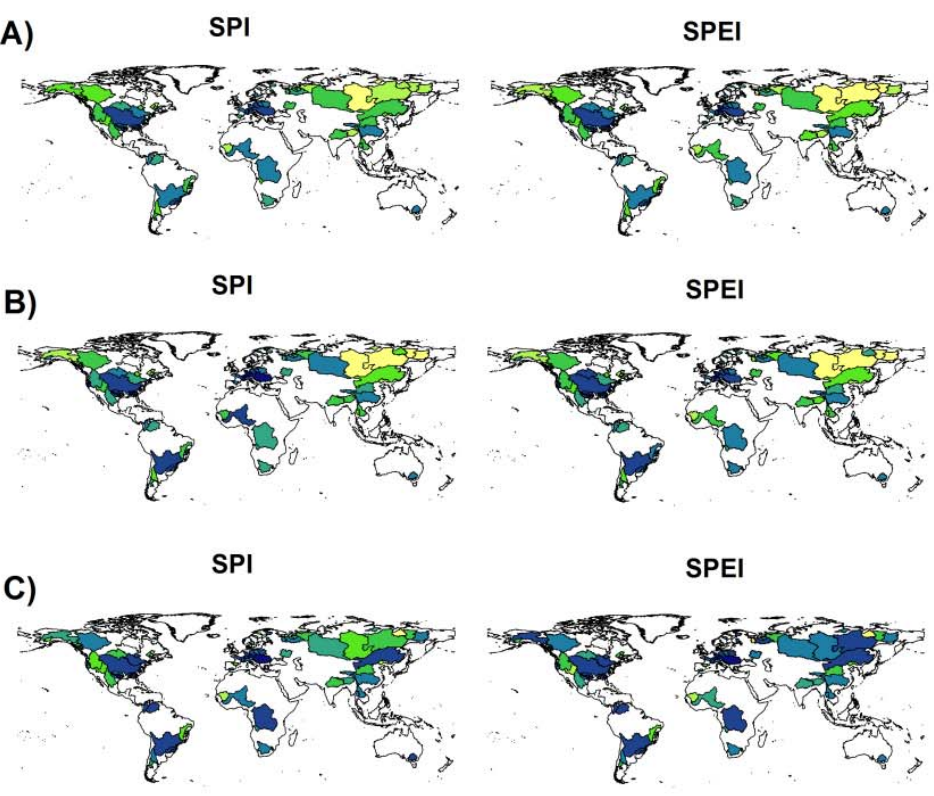

SPEI

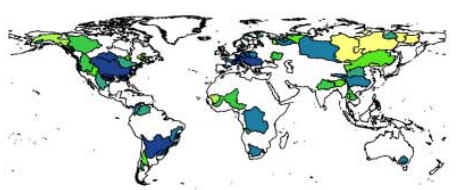

SPEI
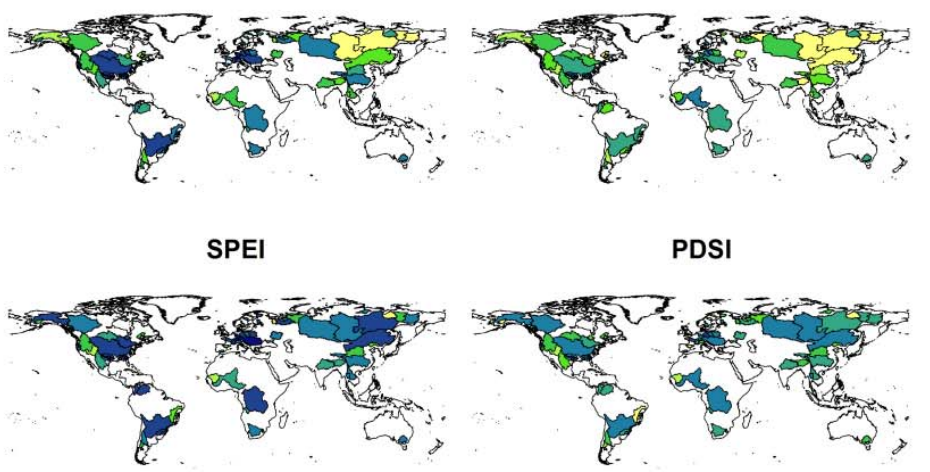

\begin{tabular}{|l|l|l|l|}
\hline 0.2 & 0.4 & 0.6 & 0.8 \\
\hline
\end{tabular}
PDSI
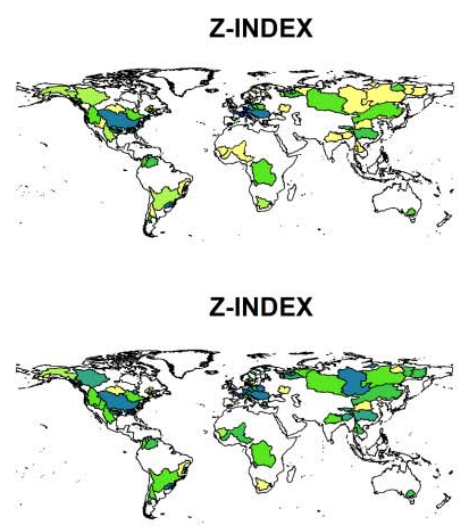

PDSI
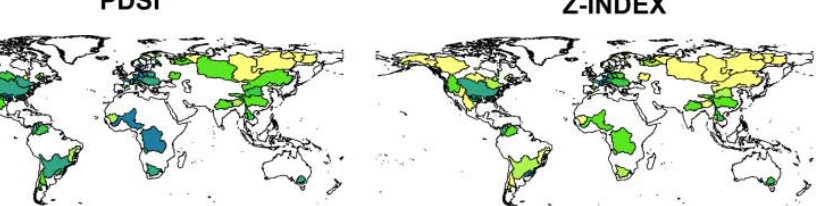

Z-INDEX

\begin{abstract}
0.8
\end{abstract}
D)

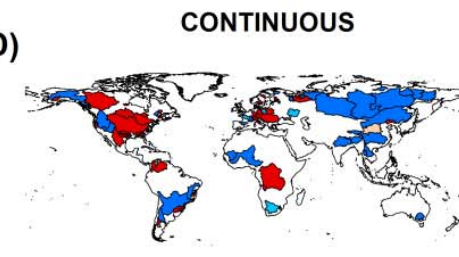

JANUARY

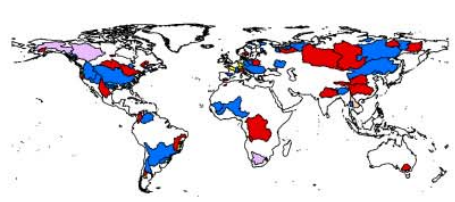

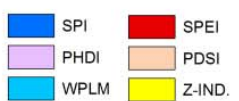

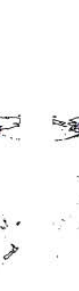

Figure 4. Spatial distribution of correlation coefficients obtained between the Standardized Streamflow Index (SSI) and several drought indices (SPI, SPEI, PDSI and Z-index). A) Correlations considering continuous series from January 1948 up to September 2004, B) Correlations considering only the January series, C) Correlations considering only the July series, D) Drought index which presented the maximum correlation with the continuous (January 1948-September 2004), January and July SSI series. 


\begin{tabular}{|l|r|r|r|r|r|r|r|r|r|r|r|r|r|}
\hline & CONTINUOUS & JAN. & FEB. & MAR. & APR. & MAY. & JUN. & JUL. & AUG. & SEP. & OCT. & NOV. & DEC. \\
\hline SPI & 38.4 & 49.0 & 57.6 & 52.3 & 48.3 & 37.1 & 31.8 & 33.8 & 29.8 & 42.4 & 57.6 & 59.6 & 53.0 \\
\hline SPEI & 44.4 & 33.1 & 31.1 & 37.7 & 40.4 & 52.3 & 54.3 & 47.0 & 53.0 & 43.0 & 31.8 & 32.5 & 30.5 \\
\hline PDSI & 4.0 & 0.7 & 2.0 & 3.3 & 3.3 & 2.0 & 4.0 & 4.6 & 6.0 & 2.6 & 1.3 & 2.6 & 2.0 \\
\hline PHDI & 0.0 & 2.0 & 1.3 & 1.3 & 2.0 & 1.3 & 2.0 & 2.0 & 2.0 & 2.6 & 0.7 & 1.3 & 2.6 \\
\hline Z-Index & 7.3 & 13.9 & 4.0 & 4.0 & 5.3 & 4.6 & 5.3 & 6.0 & 4.0 & 5.3 & 5.3 & 2.6 & 10.6 \\
\hline WPLM & 6.0 & 1.3 & 4.0 & 1.3 & 0.7 & 2.6 & 2.6 & 6.6 & 5.3 & 4.0 & 3.3 & 1.3 & 1.3 \\
\hline
\end{tabular}

Table 1: Percentage of the 151 analyzed worldwide basins at which the maximum correlation with the SSI series is found for any of the six drought indices compared. The percentages are given for the continuous SSI series and for each one of the monthly series. 

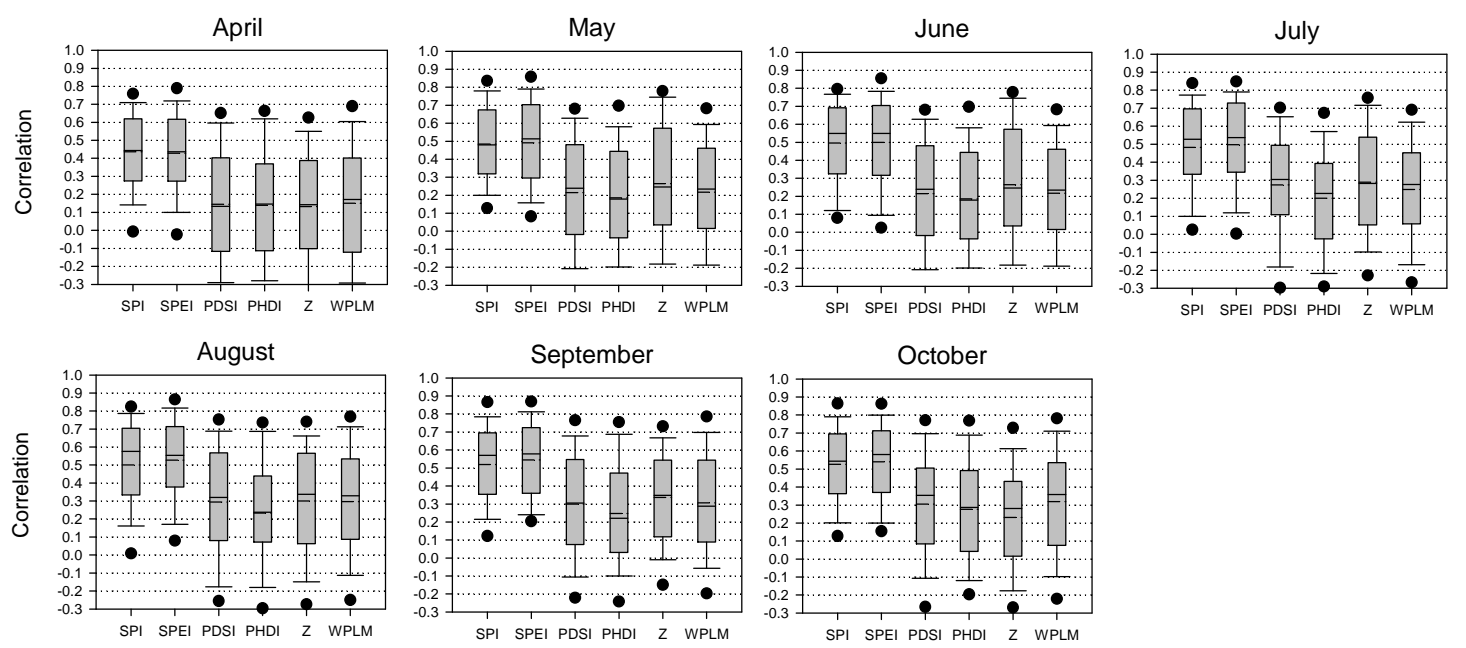

Figure 5. Box plots showing the correlation coefficients obtained between the monthly series of the Standardized Soil Moisture data in 117 sampling points across the world and the six drought indices assessed in this study. 


\begin{tabular}{|l|r|r|r|r|r|r|r|}
\hline DROUGHT INDEX & April. & May & June & July & August & September & October \\
\hline SPI & 48.3 & 43.1 & 44.8 & 31 & 31.9 & 32.8 & 42.2 \\
\hline SPEI & 44.0 & 46.6 & 44.8 & 56 & 51.7 & 49.1 & 44.0 \\
\hline PDSI & 4.3 & 3.4 & 2.6 & 6.9 & 5.2 & 3.4 & 3.4 \\
\hline PHDI & 0.9 & 2.6 & 3.4 & 0.9 & 3.4 & 3.4 & 2.6 \\
\hline Z & 1.7 & 2.6 & 2.6 & 1.7 & 4.3 & 6.0 & 3.4 \\
\hline WPLM & 0.9 & 1.7 & 1.7 & 3.4 & 3.4 & 5.2 & 4.3 \\
\hline
\end{tabular}

Table 2: Percentage of the 117 analyzed sampling points at which the maximum correlation with the standardized soil moisture series is found for any of the six drought indices compared. The percentages are given for the monthly series from April up to October. 
A)
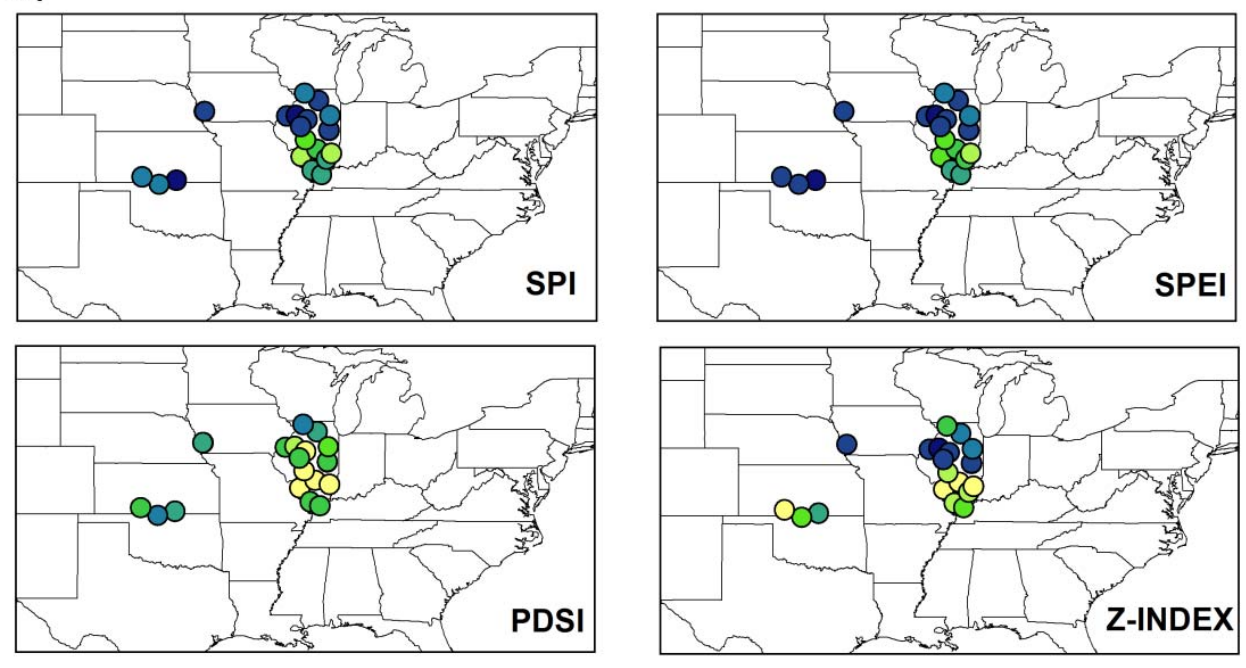

0.2

0.4

$0.6 \quad 0.8$

B)
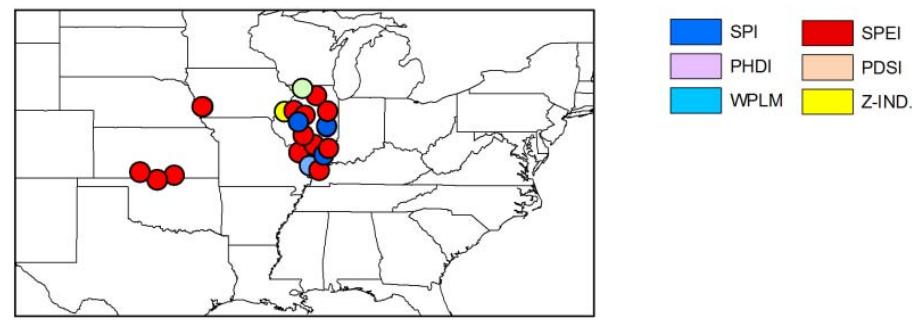

Figure 6: Spatial distribution of correlation coefficients obtained between the July soil moisture and several drought indices (SPI, SPEI, PDSI and Z-index) in North America.

A) July correlations, B) Drought index which showed the maximum correlation with soil moisture in July 


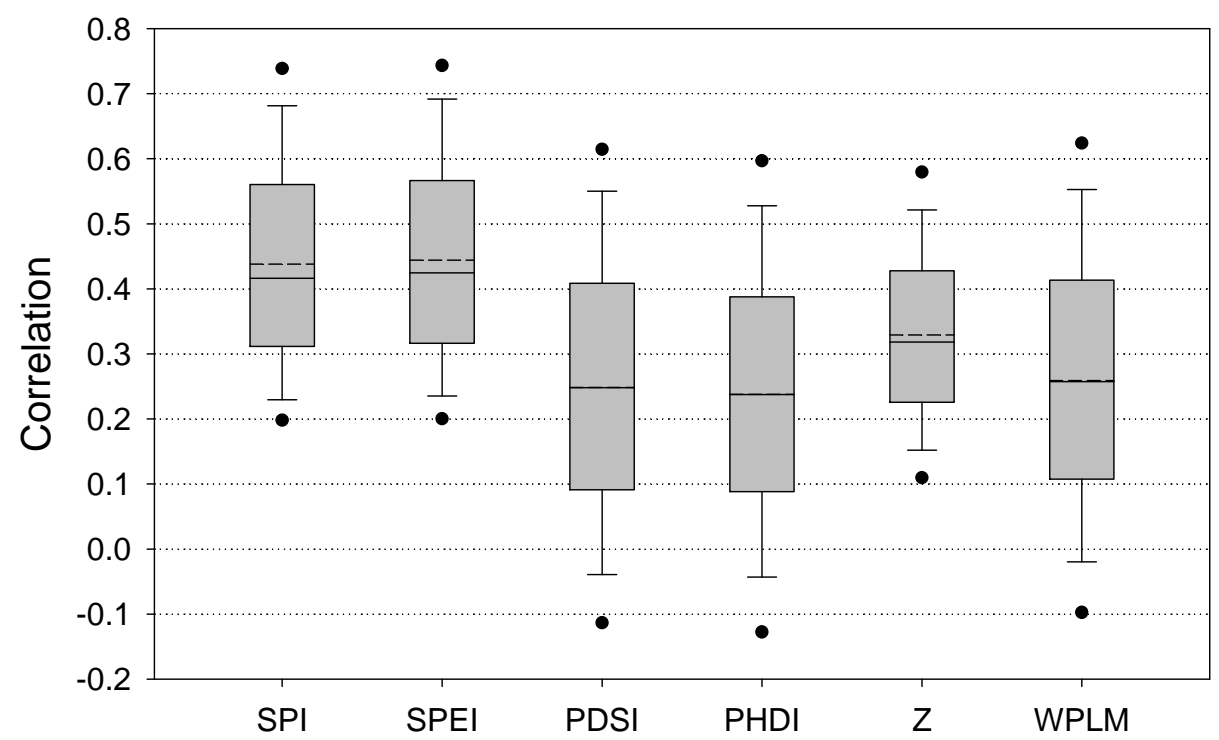

Figure 7. Box plots showing correlation coefficients obtained between the tree-ring width series in 1840 worlwide forests and the six drought indices compared in this study. The graph represents the maximum correlations found for any of the twelve monthly series. 

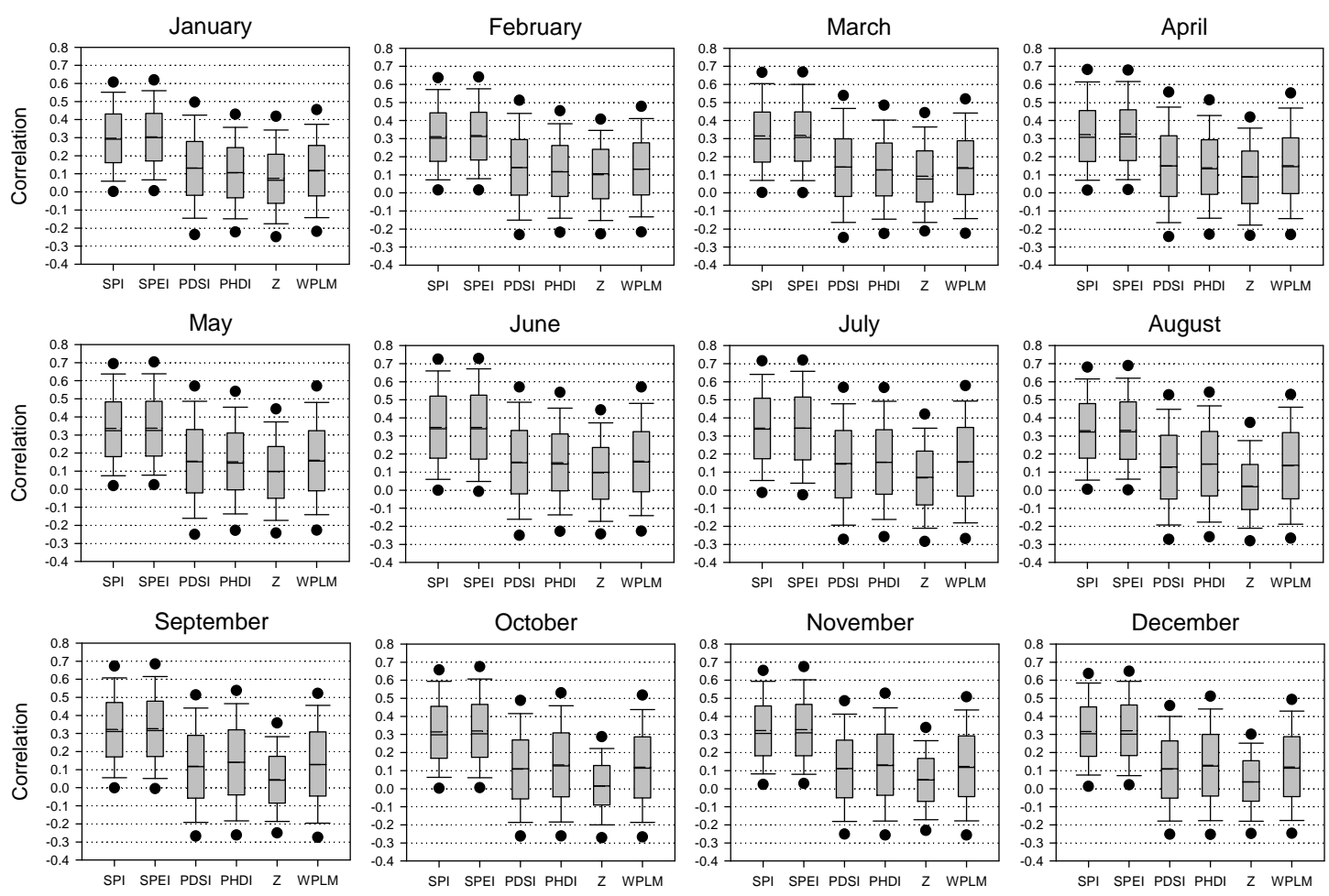

Figure 8. Box plots showing correlation coefficients obtained between the annual treering width series in 1840 forests located across the world and the monthly series of the six drought indices compared in this study. 


\begin{tabular}{|l|r|r|r|r|r|r|r|r|r|r|r|r|r|}
\hline & MAXIMUM & JAN. & FEB. & MAR. & APR. & MAY. & JUN. & JUL. & AUG. & SEP. & OCT. & NOV. & DEC. \\
\hline SPI & 37.9 & 37.3 & 38.2 & 41.1 & 41.1 & 43.4 & 43.5 & 43.3 & 43.2 & 40.9 & 41.9 & 40.0 & 42.1 \\
\hline SPEI & 48.5 & 48.4 & 49.3 & 46.3 & 46.8 & 45.2 & 46.6 & 47.3 & 48.5 & 49.5 & 49.9 & 49.9 & 49.8 \\
\hline PDSI & 2.1 & 5.7 & 4.0 & 4.5 & 4.5 & 4.3 & 2.7 & 2.4 & 2.2 & 2.2 & 1.7 & 2.1 & 2.3 \\
\hline PHDI & 2.2 & 4.5 & 3.4 & 3.5 & 3.4 & 3.6 & 3.4 & 3.9 & 3.3 & 3.9 & 3.5 & 2.8 & 3.0 \\
\hline Z & 7.0 & 3.0 & 3.9 & 3.3 & 2.2 & 2.1 & 2.2 & 1.8 & 1.5 & 2.1 & 1.6 & 4.0 & 1.4 \\
\hline WPLM & 2.4 & 1.1 & 1.4 & 1.3 & 2.0 & 1.5 & 1.6 & 1.3 & 1.3 & 1.5 & 1.4 & 1.3 & 1.3 \\
\hline
\end{tabular}

Table 3: Percentage of the 1840 analyzed tree-ring width showing the maximum correlation is found for any of the six drought indices compared. The percentages are given for the annual maximum correlations, independently of the month of the year in which they are found, and for each one of the monthly series. 

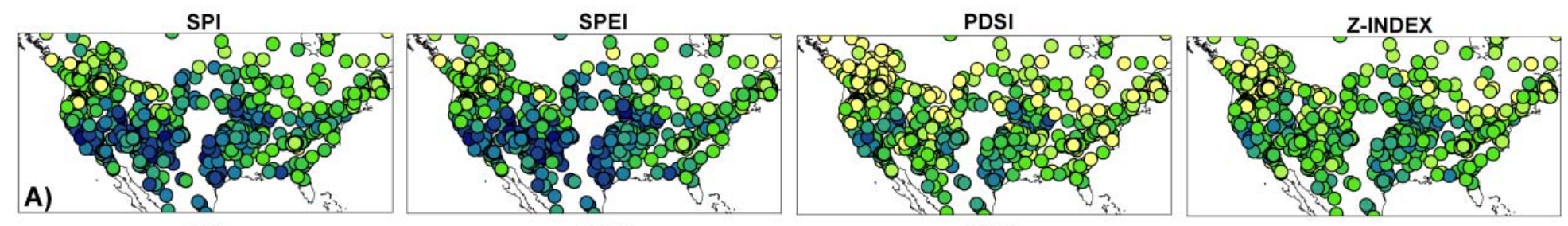

SPEI PDSI
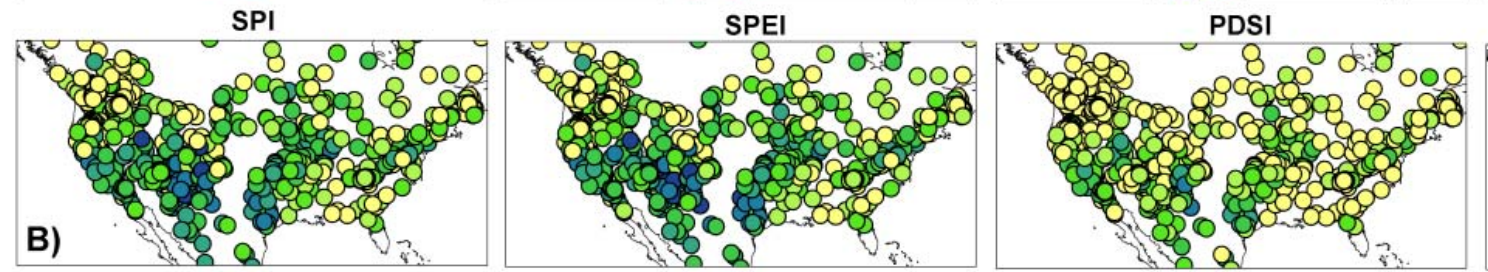

Z-INDEX

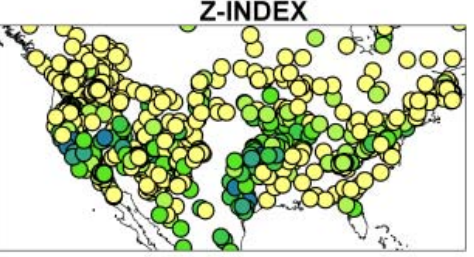

SPI
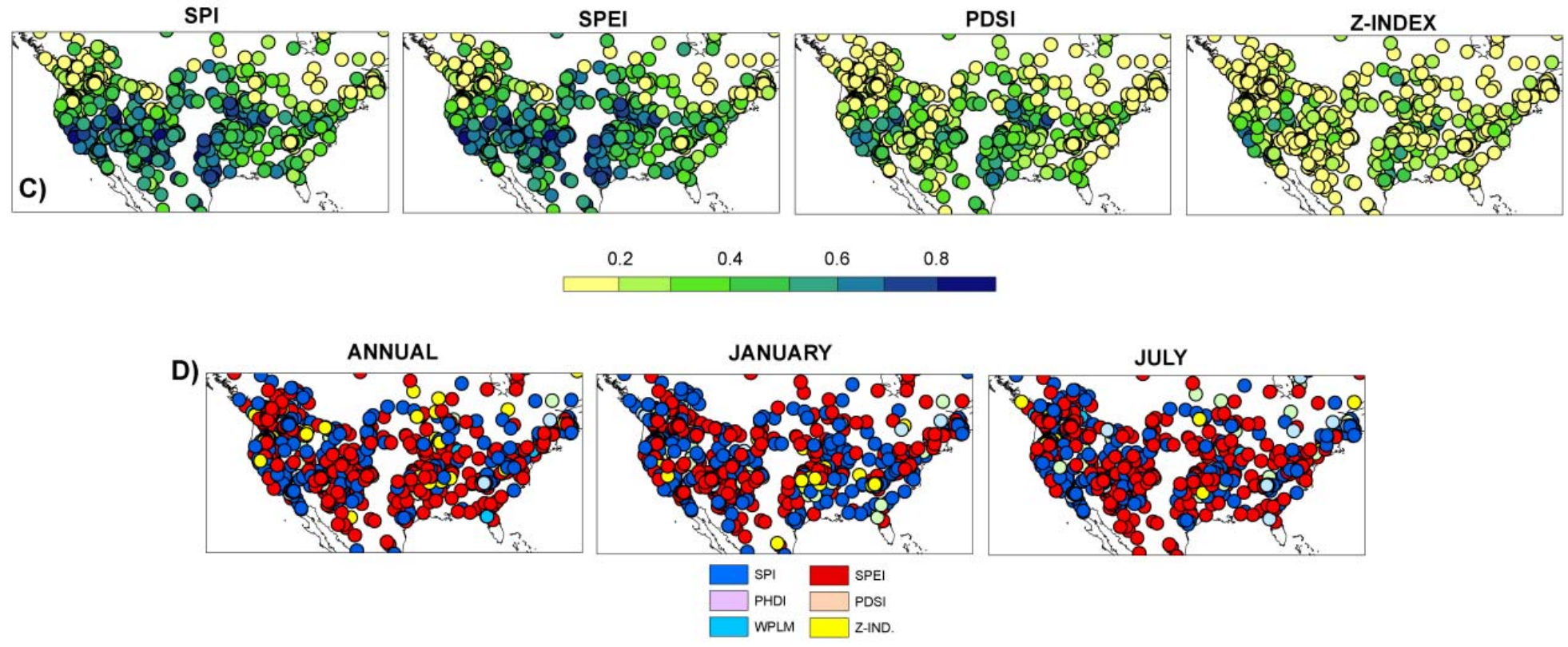

Figure 9. Spatial distribution of correlation coefficients obtained between the tree-ring width chronologies and several drought indices (SPI, SPEI, PDSI and Z-index) in the USA. A) Maximum annual correlations independently of the month of the year, B) Correlations considering only the January (B) and July (C) drought series, D) Drought index showing the maximum correlation with tree growth for the annual, January and July drought series. 


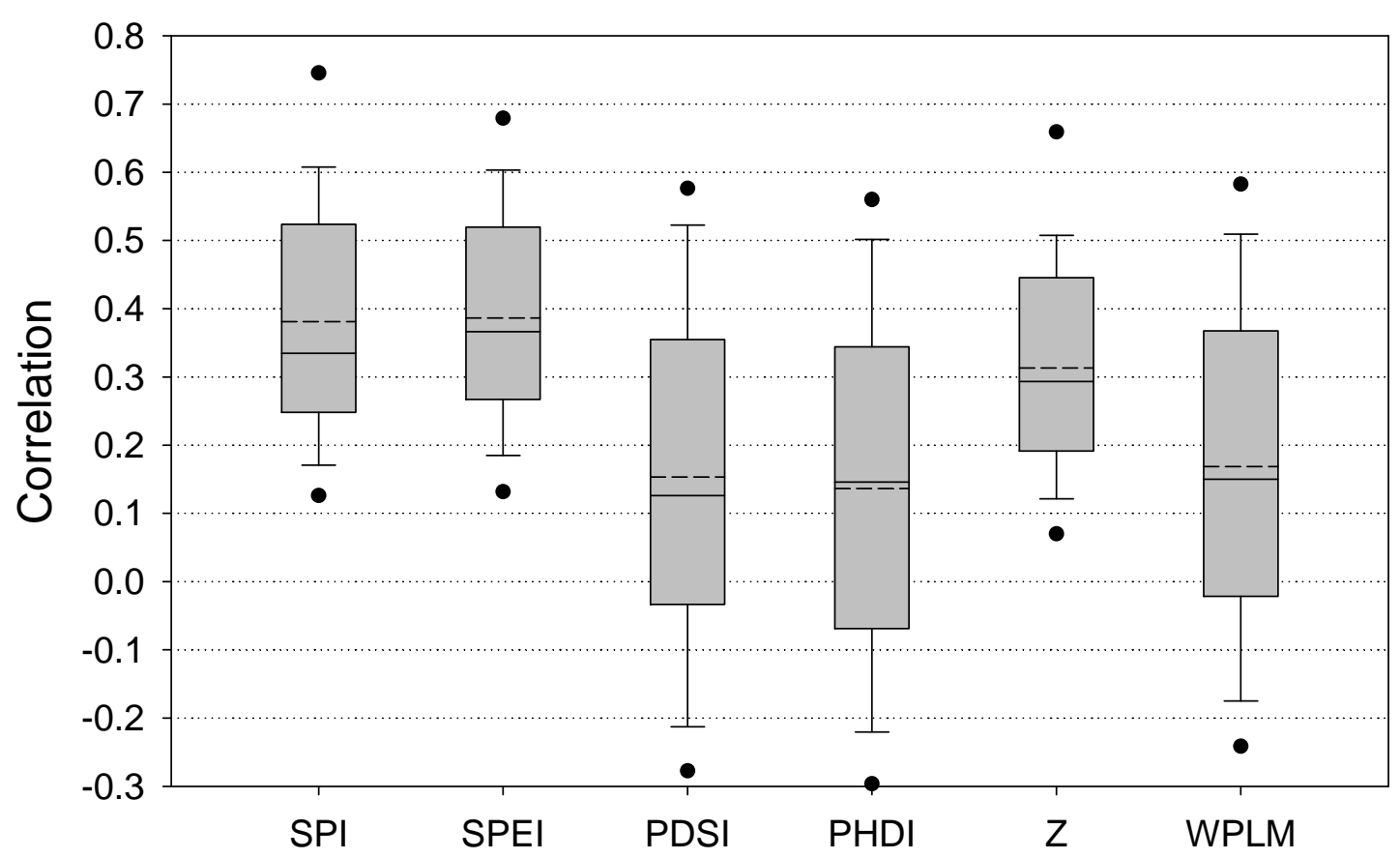

Figure 10. Box plots showing correlation coefficients between the wheat yields in 173 countries and the six drought indices compared in this study. The graph represents the maximum correlations found for any of the twelve monthly series. 
A)

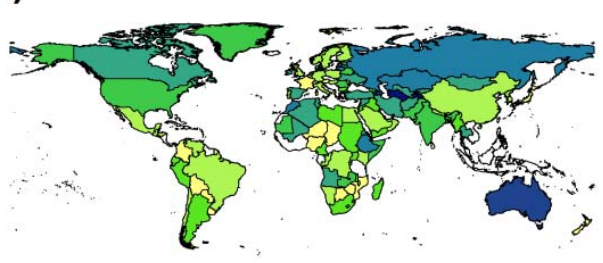

PDSI

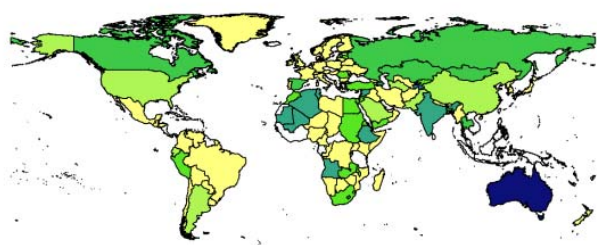

0.2

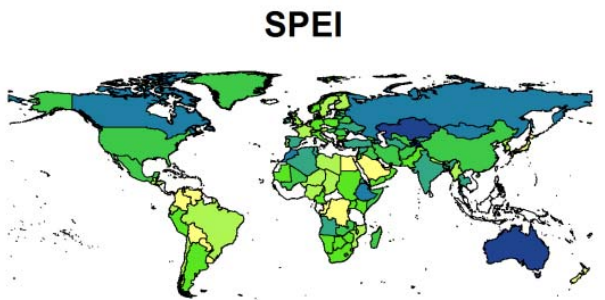

Z-INDEX

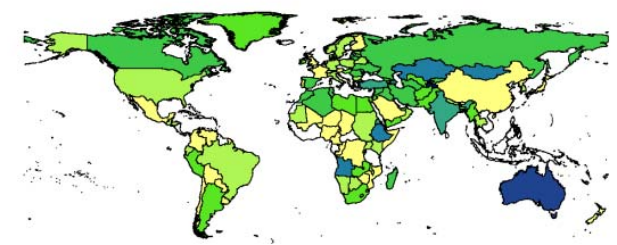

0.8

B)

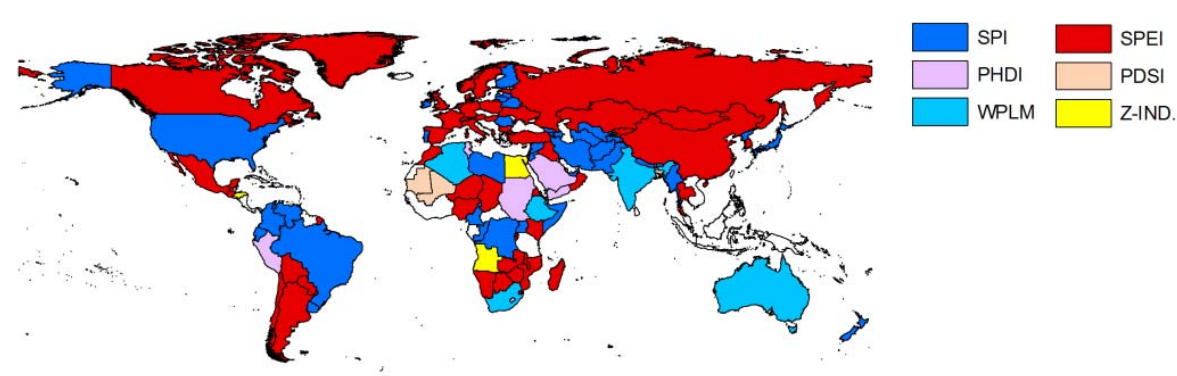

Figure 11: Spatial distribution of correlation coefficients obtained between the annual wheat yields and several drought indices (SPI, SPEI, PDSI and Z-index). A) Maximum annual correlations independently of the month of the year, B) Drought index showing the maximum correlation with crop yield for the different monthly series of the drought indices. The countries with white areas lack wheat cultivation or do not have available long time series of wheat yields. 